\title{
Ion Complexation in Nonactin, Monactin, and Dinactin: A Raman Spectroscopic Study
}

\author{
IRVIN M. ASHER, ${ }^{*}$ GEORGE D. J. PHILLIES ${ }^{\dagger}$ B. J. KIM,$\ddagger$ and H. E. \\ STANLEY, Harvard-M.I.T. Program in Health Sciences and \\ Technology and Department of Physics, Massachusetts Institute of \\ Technology, Cambridge, Massachusetts 02139
}

\begin{abstract}
Synopsis
The ability of the macrotetrolide nactins to complex selectivity with a wide variety of cations makes these ionophorous antibiotics important model systems for the study of biologic ionic transport. We report a Raman spectroscopic investigation of the $\mathrm{Na}^{+}, \mathrm{K}^{+}, \mathrm{Rb}^{+}, \mathrm{Cs}^{+}, \mathrm{Tl}^{+}$, $\mathrm{NH}_{4}{ }^{+}, \mathrm{NH}_{3} \mathrm{OH}^{+}, \mathrm{C}\left(\mathrm{NH}_{2}\right)_{3}{ }^{+}$, and $\mathrm{Ba}^{++}$complexes of nonactin, monactin, and dinactin in $4: 1$ $(\mathrm{v} / \mathrm{v}) \mathrm{CH}_{3} \mathrm{OH} / \mathrm{CHCl}_{3}$ and in the solid state. The nactins display characteristic spectral changes upon complexation, some of which are specific for a given cation. In the $\mathrm{K}^{+}, \mathrm{Rb}^{+}$, $\mathrm{Cs}^{+}, \mathrm{NH}_{3} \mathrm{OH}^{+}$, and $\mathrm{C}\left(\mathrm{NH}_{2}\right)_{3}{ }^{+}$complexes, which are apparently isosteric, the ester carbonyl stretch frequency is found to be linearly proportional to the cation-carbonyl electrostatic interaction energy, as calculated from a simplified model. Deviations for the $\mathrm{Na}^{+}, \mathrm{NH}_{4}{ }^{+}$, $\mathrm{Tl}^{+}$, and $\mathrm{Ba}^{++}$complexes are interpreted as arising from additional nonelectrostatic interactions. Additional information is obtained from other spectral regions and from measurements of depolarization ratios. Spectra of the nactin complexes differ from each other more in the solid state than in solution, reflecting the effects of crystalline contact forces.
\end{abstract}

\section{INTRODUCTION}

The macrotetrolide nactins [Fig. 1(a)] are a family of macrocyclic ionophorous antibiotics whose ability to complex, selectively, a wide variety of cations ${ }^{1-3}$ has made them particularly interesting in the study of selective ion transport. In solution, the individual uncomplexed nactin molecules apparently adopt a relatively open, flat, flexible set of conformations. ${ }^{3}$ However, upon complexation, the nactin molecule is believed to take on a single, relatively rigid conformation similar to that found in crystalline nactin complexes ${ }^{4-7}[\mathrm{Fig} .1(\mathrm{~b})]$. The cation is located at the center of the complex, faced by the four ester and the four ether oxygen atoms. The remainder of the nactin molecule is so arranged that the complex presents a hydrophobic exterior to the solvent, which may explain the ability of the nactins to facilitate the extraction of ions into nonpolar solvents.

\footnotetext{
* Present address: Office of Science, HFS-50, U.S. Food and Lrug Administration, HEW, Rockville, Maryland 20852.

† Present address: Department of Chemistry, University of California Los Angeles, Los Angeles, California 90024 .

$\ddagger$ Present address: Department of Physiology, Boston University Medical School, Boston, Mass. 02118.
} 


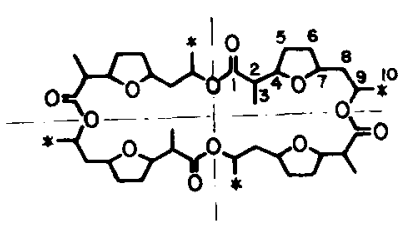

(a)

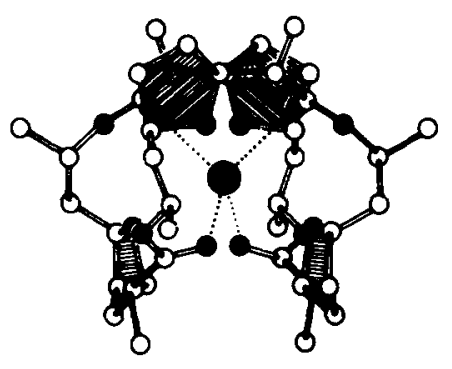

(b)

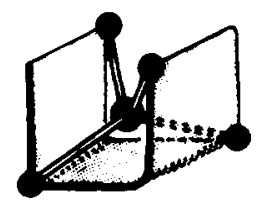

(c)

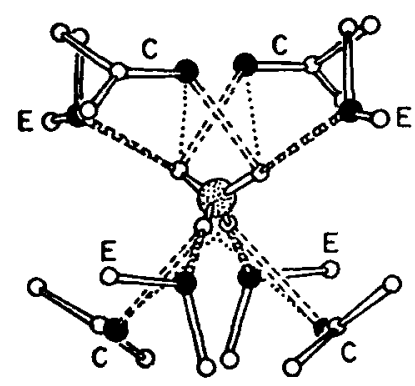

(d)

Fig. 1. (a) Chemical structure of nonactin. In monactin, one of the asterisked methyl groups is replaced with an ethyl group. There are two such replacements in dinactin, three in trinactin, and four in tetranactin. Carbon atoms are numbered for reference in text. (b) X-ray crystallographic structure of the nonactin- $\mathrm{K}^{+}$complex (after Ref. 5). (c) Simplified schematic drawing of the coordination of a cation to the ester carbonyl groups of nonactin, emphasizing the tetrahedral symmetry of the ester carbonyl groups. (d) Coordination and hydrogen bonding of $\mathrm{NH}_{4}{ }^{+}$to the carbonyl (C) and tetrahydrofuran (E) oxygen atoms of tetranactin (after Ref. 7).

The available X-ray crystallographic data are summarized in Table I. In the nonactin- $\mathrm{K}^{+}$comple ${ }^{5}$ [Fig. 1(b)], the cation is tetrahedrally coordinated [Fig. 1(c)] by the four ester carbonyl groups. The structure of crystalline nonactin- $\mathrm{Na}^{+}$complex ${ }^{8}$ is found to be similar, although the internal cavity is found to be substantially larger than the $\mathrm{Na}^{+}$ion it contains. Similar structures are found for crystalline tetranactin complexed with $\mathrm{K}^{+}, \mathrm{Na}^{+}$, and $\mathrm{Rb}^{+}{ }^{6}$ The mean cation-carbonyl oxygen distance is only slightly less than the mean cation-ether oxygen distance in the $\mathrm{K}^{+}$and $\mathrm{Rb}^{+}$complexes of tetranactin (Table I), but it is some $0.4 \AA$ smaller in the $\mathrm{Na}^{+}$complex. This suggests that the positions of the ether oxygens may be limited by steric factors in the $\mathrm{Na}^{+}$complex.

In contrast, a recent $\mathrm{X}$-ray study of the tetranactin- $\mathrm{NH}_{4}{ }^{+}$complex ${ }^{7}$ reports hydrogen bonding between the $\mathrm{NH}_{4}{ }^{+}$ion and the tetrahydrofuran ether oxygens of tetranactin [Fig. 1(d)]. The cation-ether oxygen distance is $\sim 0.12 \AA$ smaller than the cation-carbonyl oxygen distance; the $\mathrm{NH}_{4}{ }^{+}$ protons are aligned on the ether oxygen atoms (and at about $75^{\circ}$ to the $\mathrm{C}=\mathrm{O}$ bond). The $\mathrm{NH}_{4}{ }^{+}$-ether hydrogen bonds may account for the great stability of the nonactin- $\mathrm{NH}_{4}{ }^{+}$complex, as observed in extraction experiments. ${ }^{1}$ 
Equilibrium constants for nactin complexation have been obtained from studies of the extraction of alkali salts from aqueous to nonpolar bulk phases $^{1}$ and from proton magnetic resonance studies. ${ }^{3}$ The selectivity sequence for nonactin is found to be $\mathrm{NH}_{4}{ }^{+}>\mathrm{K}^{+}>\mathrm{Rb}^{+}>\mathrm{Cs}^{+}>\mathrm{Na}^{+}>$ $\mathrm{Li}^{+}$. As noted by Eisenman et al., the measurement of intrinsic binding constants with extraction experiments requires the assumption that the solution conformations of the various cation complexes are basically identical (i.e., "isosteric"). The test of this assumption is one of the motivations of the present work.

In a previous paper, ${ }^{9}$ we reported a Raman spectroscopic study of uncomplexed nonactin, monactin, dinactin, trinactin, and tetranactin in the solid state and $\mathrm{CCl}_{4}, \mathrm{CHCl}_{3}, \mathrm{CH}_{3} \mathrm{OH}$, and $4: 1(\mathrm{v} / \mathrm{v}) \mathrm{CH}_{3} \mathrm{OH} / \mathrm{CHCl}_{3}$ solution. Comparison with model compounds permitted the identification of most spectral features. The conformation of crystalline monactin was found to be similar to that of uncomplexed nonactin and tetranactin (whose atomic coordinates are known), ${ }^{10,11}$ while dinactin and trinactin were found to have a second, distinct, crystal structure. In contrast, the solution spectra of uncomplexed nonactin, monactin, and dinactin were similar. The solution conformation is evidently relatively open, allowing the formation of hydrogen bonds between solvent molecules and nactin ester carbonyl groups.

In the present work, we extend this study to the complexes of nonactin, monactin, and dinactin with $\mathrm{Na}^{+}, \mathrm{K}^{+}, \mathrm{Rb}^{+}, \mathrm{Cs}^{+}, \mathrm{Tl}^{+}, \mathrm{NH}_{4}{ }^{+}, \mathrm{NH}_{3} \mathrm{OH}^{+}$, $\mathrm{C}\left(\mathrm{NH}_{2}\right)_{: 3}{ }^{+}$, and $\mathrm{Ba}^{++}$. Spectra of the monovalent complexes were obtained both in $4: 1(\mathrm{v} / \mathrm{v}) \mathrm{CH}_{3} \mathrm{OH} / \mathrm{CHCl}_{3}$ solution and in the solid state. Depolarization ratios were measured in solution. Some of our data on nonactin complexes have been reported in preliminary notes; ${ }^{12,13}$ our results indi-

TABLE I

Summary of X-Ray Data

\begin{tabular}{|c|c|c|c|c|c|c|}
\hline Nactin & Cation & $Z$ & Space Group & $\mathrm{M}^{+} \ldots \mathrm{O}=\mathrm{C}$ & $\mathrm{M}^{+} \ldots \mathrm{O}_{\mathrm{C}}^{\mathrm{C}}$ & $\begin{array}{l}\text { Refer- } \\
\text { ence }\end{array}$ \\
\hline Nonactin & - & 8 & $\begin{array}{l}\text { order-disorder } \\
\text { structure }\end{array}$ & - & - & 10 \\
\hline Nonactin & $\mathrm{Na}^{+}$ & 4 & $C 2 / C$ & 2.42 & 2.77 & 8 \\
\hline Nonactin & $\mathrm{K}^{+}$ & 4 & Pnna & 2.81 & 2.81 & 5 \\
\hline Tetranactin & - & 4 & $C 2 / c$ & - & - & 29 \\
\hline Tetranactin & $\mathrm{Na}^{+}$ & 8 & $C 2 / c$ & 2.435 & 2.820 & 6 \\
\hline Tetranactin & $\mathrm{K}^{+}$ & 4 & $P 2_{1} / n$ & 2.789 & 2.893 & 6 \\
\hline Tetranactin & $\mathrm{K}^{+}$ & 8 & $C 2 / c$ & 2.774 & 2.874 & 6 \\
\hline Tetranactin & $\mathrm{Rb}^{+}$ & 4 & $P 2_{1} / n$ & 2.909 & 2.940 & 6 \\
\hline Tetranactin & $\mathrm{NH}_{4}{ }^{+}$ & 4 & $P 2_{1} / n$ & 3.010 & 2.894 & 7 \\
\hline Tetranactin & $\mathrm{Ba}^{++}$ & 8 & $P 2_{1} / a$ & 一 & - & 29 \\
\hline Tetranactin & $\mathrm{Cu}^{++}$ & 8 & $P 2_{1} / a$ & - & - & 29 \\
\hline
\end{tabular}

a Note: $\quad Z=$ number of nactin molecules/unit cell. The fifth and sixth columns give the mean distances $(\AA)$ between the enclosed metal ion $\left(\mathrm{M}^{+}\right)$and the carbonyl $(\mathrm{O}=\mathrm{C})$ and ether $(\mathrm{C}-\mathrm{O}-\mathrm{C})$ oxygens. 


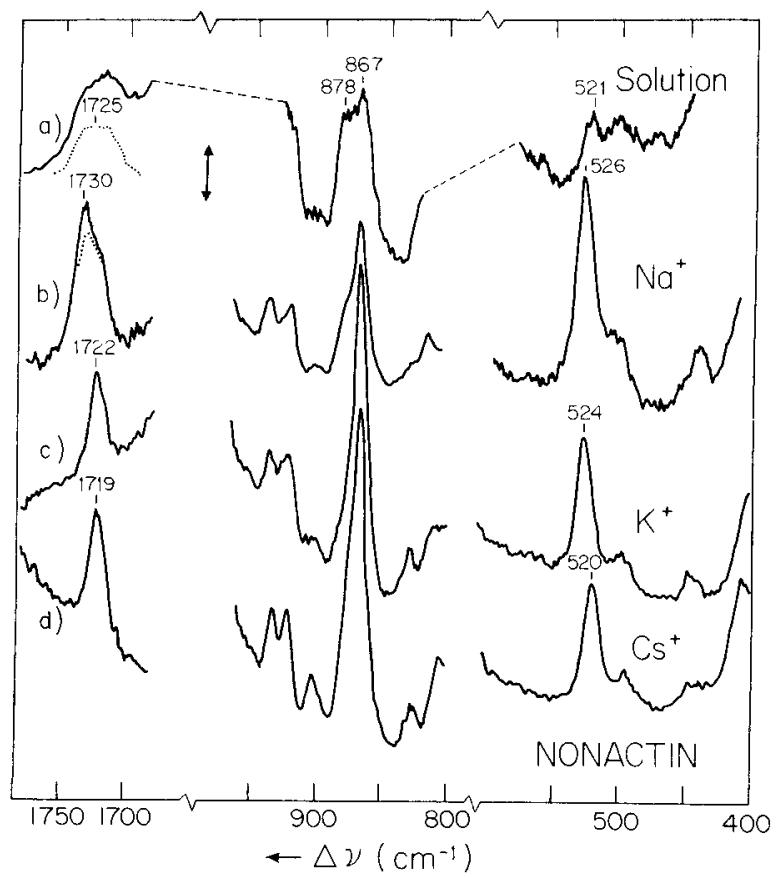

Fig. 2. Raman spectra of (a) uncomplexed nonactin and its (b) $\mathrm{Na}^{+}$, (c) $\mathrm{K}^{+}$, and (d) $\mathrm{Cs}^{+}$ complexes in 4:1 (v/v) $\mathrm{CH}_{33} \mathrm{OH} / \mathrm{CHCl}_{3}$. Vertical arrow represents (a), (b) 100 counts/sec, (c), (d) 300 counts $/ \mathrm{sec}$, except [(b), $\left.800-950 \mathrm{~cm}^{-1}\right] 300$ counts $/ \mathrm{sec}$. Scanning speed $30 \mathrm{~cm}^{-1} / \mathrm{min}$, slit width $\sim 4 \mathrm{~cm}^{-1}$, incident power $100-140 \mathrm{~mW}$, and incident wavelength (a) $5145 \AA$, (b)-(d), $4880 \AA$. Solvent peaks obscure the intervening spectral regions.

cated that the cation-nactin ester carbonyl interaction is primarily electrostatic.

Our basic objective is to use Raman spectroscopy to study molecular conformation and molecular interactions in the cation complexes of the nactins. Since Raman spectroscopy can be applied both to solutions and to crystals, we are able to compare our results with the detailed structural information provided by X-ray diffraction on solid-state systems and to extend such results to the investigation of nactin conformations in solution.

\section{METHODS AND MATERIALS}

Raman spectra were measured using a SPEX Ramalog 4 double-grating monochromator system and the 4579,4880 or $5145 \AA$ line of a Spectra Physics Model 164-03 argon ion laser. Samples were held in Kimax glass capillaries mounted perpendicularly to the scattering plane; the polarization vector of the incident laser light was also perpendicular to the scattering plane. Laser powers of 20-100 mW (crystals) or 50-200 mW (solutions), 


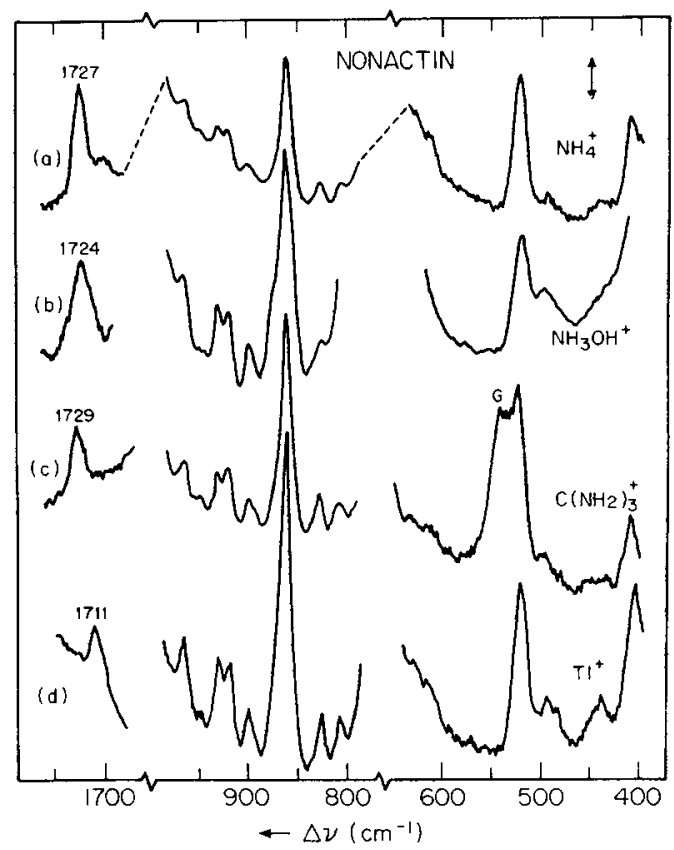

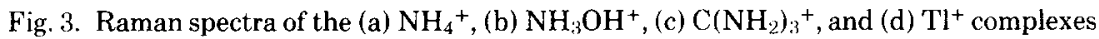
of nonactin in $4: 1(\mathrm{v} / \mathrm{v}) \mathrm{CH}_{3} \mathrm{OH} / \mathrm{CHCl}_{3}$. Vertical arrow represents 300 counts $/ \mathrm{sec}$, except $\left[(\mathrm{a}), 800-1000 \mathrm{~cm}^{-1}\right] 500$ counts $/ \mathrm{sec},\left[(\mathrm{c}), 800-1000 \mathrm{~cm}^{-1}\right] 100 \mathrm{counts} / \mathrm{sec}$, and $[(\mathrm{d}), 400-1000$ $\left.\mathrm{cm}^{-1}\right] 100$ counts $/ \mathrm{sec}$. Scanning speed $30 \mathrm{~cm}^{-1} / \mathrm{min}$, slit width $\sim 5 \mathrm{~cm}^{-1}$, incident power $80-140 \mathrm{~mW}$, and incident wavelength $4880 \AA$, except [(a), 400-600 and $\left.1650-1750 \mathrm{~cm}^{-1}\right] 4579$ A.

scanning speeds of $30-60 \mathrm{~cm}^{-1} / \mathrm{min}$, and a spectral resolution of $5 \mathrm{~cm}^{-1}$ were used.

Polarization effects were studied using a polarization analyzer placed between the sample and the polarization scrambler, which was permanently mounted in front of the monochromator entrance slit.

In what follows, spectra of Raman scattered light with polarization parallel and perpendicular to that of the incident beam will be referred to as the "polarized" and "depolarized" spectra, respectively (hereafter denoted "\|" and " $\perp$ ", respectively). One can then assign each Raman peak a polarization ratio $\rho \equiv I_{\perp} / I_{\|}$, where $I_{\perp}$ and $I_{\|}$are the intensities observed in the $\perp$ and $\|$ spectra, respectively. Under nonresonant conditions, $\rho$ can never exceed $3 / 4$. If $\rho=3 / 4$, the peak is said to be "depolarized;" if $\rho=0$, "polarized;" and if $0<\rho<3 / 4$, "partially polarized."14 Occasionally, peaks (labeled " $D$ " in Tables IM-VM*) are more clearly observed in the depolarized spectrum $(\perp)$ than in the polarized spectrum $(\|)$. This is not a

* Tables IM-VM, detailing the spectral characteristics of nonactin, monactin, and dinactin complexes in solution, and monactin crystalline, and dinactin crystalline complexes have been stored in a microfiche repository. Readers wishing to obtain copies of these tables may do so by writing to Manager, Journal Production Department, John Wiley \& Sons, Inc., 605 Third Avenue, New York, N.Y. 10016. 


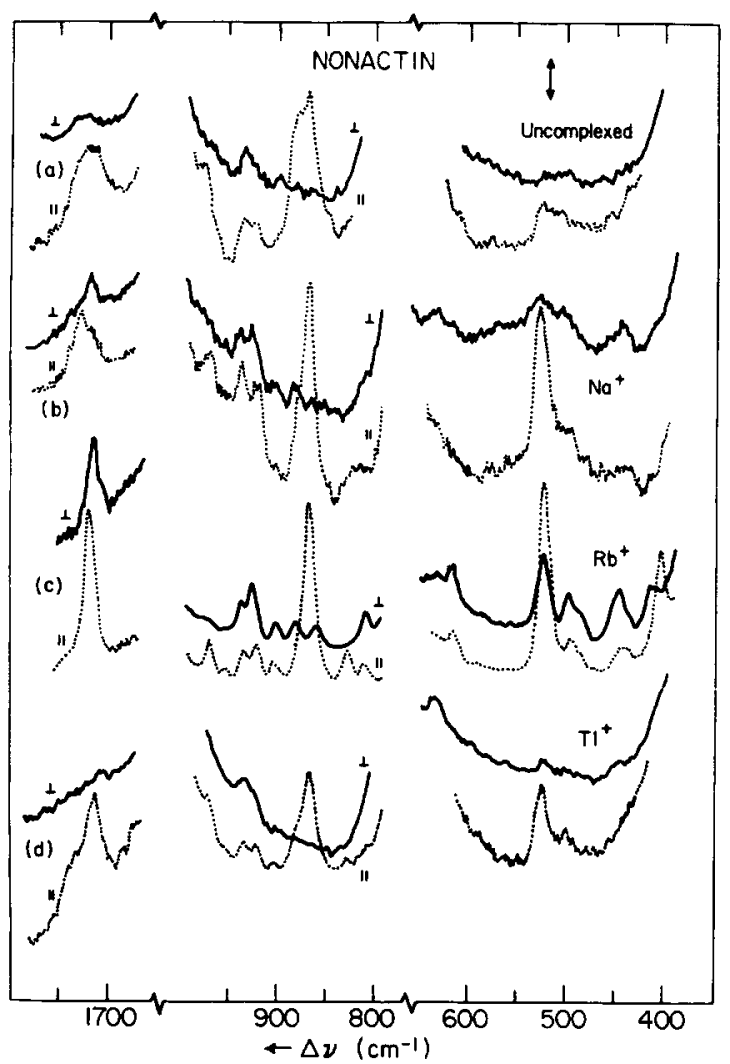

Fig. 4. Polarized $(\|)$ and depolarized $(\perp)$ Raman spectra of (a) uncomplexed nonactin in 2:1 (v/v) $\mathrm{CH}_{3} \mathrm{OH} / \mathrm{CHCl}_{3}$ nd its (b) $\mathrm{Na}^{+}$, (c) $\mathrm{Rb}^{+}$, and (d) $\mathrm{Tl}^{+}$complexes in 4:1 (v/v) $\mathrm{CH}_{3} \mathrm{OH} /$ $\mathrm{CHCl}_{3}$. (Uncomplexed nonactin is less soluble in $\mathrm{CH}_{3} \mathrm{OH}$ than its complexes.) Vertical arrow represents 100 counts $/ \mathrm{sec}$, except: [(b), $\left.1,1650-1750 \mathrm{~cm}^{-1}\right] 30$ counts $/ \mathrm{sec}$, [(b), $11,400-600$ $\left.\mathrm{cm}^{-1}\right] 140$ counts $/ \mathrm{sec},\left[(\mathrm{b}), \|, 800-1000 \mathrm{~cm}^{-1}\right] 200 \mathrm{counts} / \mathrm{sec},\left[(\mathrm{c}), \|, 400-600,1650-1750 \mathrm{~cm}^{-1}\right.$, and (c), $\left.\perp, 800-1000 \mathrm{~cm}^{-1}\right] 300$ counts/sec, [(d), $\left.\|, 800-1000 \mathrm{~cm}^{-1}\right] 300 \mathrm{counts} / \mathrm{sec}$, and [(c), $\|, 800-1000 \mathrm{~cm}^{-1}$ ], 1000 counts $/ \mathrm{sec}$. Scanning speed $30 \mathrm{~cm}^{-1} / \mathrm{min}$, slit width $\sim 5 \mathrm{~cm}^{-1}$, incident power $\sim 250 \mathrm{~mW}$, and incident wavelength $5145 \AA$, except (a) $4880 \AA$. Note that the depolarized spectra were generally taken with a higher instrumental sensitivity than the polarized spectra.

violation of the requirement $\rho \leqslant 3 / 4$; rather this effect arises because a decrease in the intensity of a polarized band in the $\perp$ spectrum may unmask nearby depolarized bands.

The nonactin was the gift of Dr. B. Stearns of the Squibb Institute for Medical Research (Princeton, New Jersey); the monactin and dinactin were gifts of Dr. H. Bickel and Dr. K. Scheibli of Ciba-Geigy, Ltd. (Basel, Switzerland). Crystals of tetranactin-Ba ${ }^{++}$were kindly provided by $\mathrm{Dr}$. $\mathrm{K}$. Ando and Dr. Y. Nawata of Chugai Pharmaceutical Company, Ltd. (Tokyo, Japan). All were used without further purification. The solvent mixture of 4:1 (v/v) $\mathrm{CH}_{3} \mathrm{OH} / \mathrm{CHCl}_{3}$ was chosen to provide sufficient solubility of 


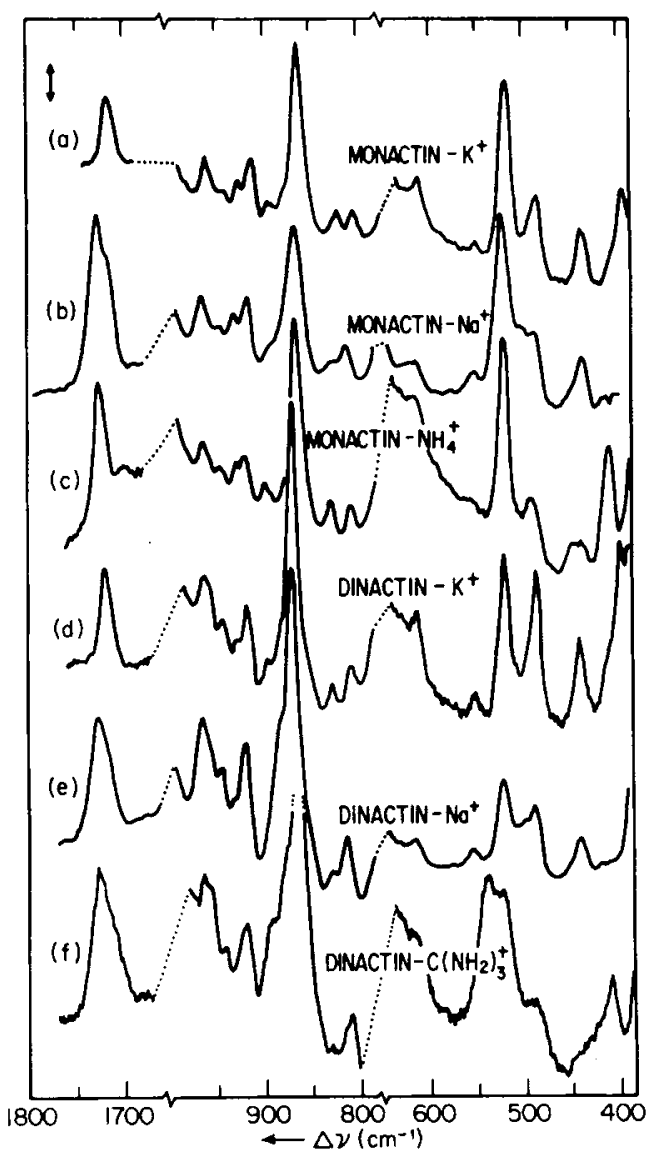

Fig. 5. Raman spectra of the (a) $\mathrm{K}^{+}$, (b) $\mathrm{Na}^{+}$, and (c) $\mathrm{NH}_{4}{ }^{+}$complexes of monactin, and the (d) $\mathrm{K}^{+}$, (e) $\mathrm{Na}^{+}$, and (f) $\mathrm{C}\left(\mathrm{NH}_{2}\right)_{3}{ }^{+}$complexes of dinactin in $4: 1(\mathrm{v} / \mathrm{v}) \mathrm{CH}_{3} \mathrm{OH} / \mathrm{CHCl}_{3}$. The other complexes resemble the corresponding $\mathrm{K}^{+}$complex. Vertical arrow represents [(a)-(c), 400-600, 1650-1750 $\left.\mathrm{cm}^{-1}\right] 300$ counts/sec, [(a)-(c), 800-1000 $\left.\mathrm{cm}^{-1}\right] 1000$ counts $/ \mathrm{sec}$, [(d), (f), $400-600 \mathrm{~cm}^{-1}$ ] 100 counts/sec, [(d), (f), 800-1800 $\mathrm{cm}^{-1}$ )] 300 counts/sec, and (e) 1000 counts $/ \mathrm{sec}$. Notice that the relative intensity of the band near $525 \mathrm{~cm}^{-1}$ decreases in the series nonactin, monactin, and dinactin. Scanning speed $30 \mathrm{~cm}^{-1} / \mathrm{min}$, slit width $\sim 4 \mathrm{~cm}^{-1}$, incident power $\sim 200 \mathrm{~mW}$, incident wavelength (a)-(c) $5145 \AA$, (d)-(f) $4880 \AA$.

both the nactins and salts; it provided an unobstructed view of the 400-650, $800-975$, and $1600-1800 \mathrm{~cm}^{-1}$ spectral regions. Solvents were spectroscopic grade or equivalent.

Solutions (usually $0.03 \mathrm{M}$ nactin, $0.5 \mathrm{M}$ salt) were prepared directly in capillaries and lightly centrifuged. Crystalline samples were obtained by letting the solvent slowly evaporate from the capillary, permitting the nactin-cation complexes to recrystallize in the presence of excess salt. The salts used were $\mathrm{NaSCN}, \mathrm{NaNO}_{3}, \mathrm{KSCN}, \mathrm{KNO}_{3}, \mathrm{KCl}, \mathrm{RbNO}_{3}, \mathrm{RbCl}, \mathrm{CsCl}$, $\mathrm{TINO}_{33}, \mathrm{TlCl}, \mathrm{NH}_{4} \mathrm{SCN}, \mathrm{NH}_{4} \mathrm{NO}_{3}, \mathrm{NH}_{3} \mathrm{OHCl}, \mathrm{C}\left(\mathrm{NH}_{2}\right)_{3} \mathrm{Cl}, \mathrm{Ba}(\mathrm{SCN})_{2}$, and $\mathrm{Ba}\left(\mathrm{ClO}_{4}\right)_{2}$. The anions affected the formation constant of the observed 


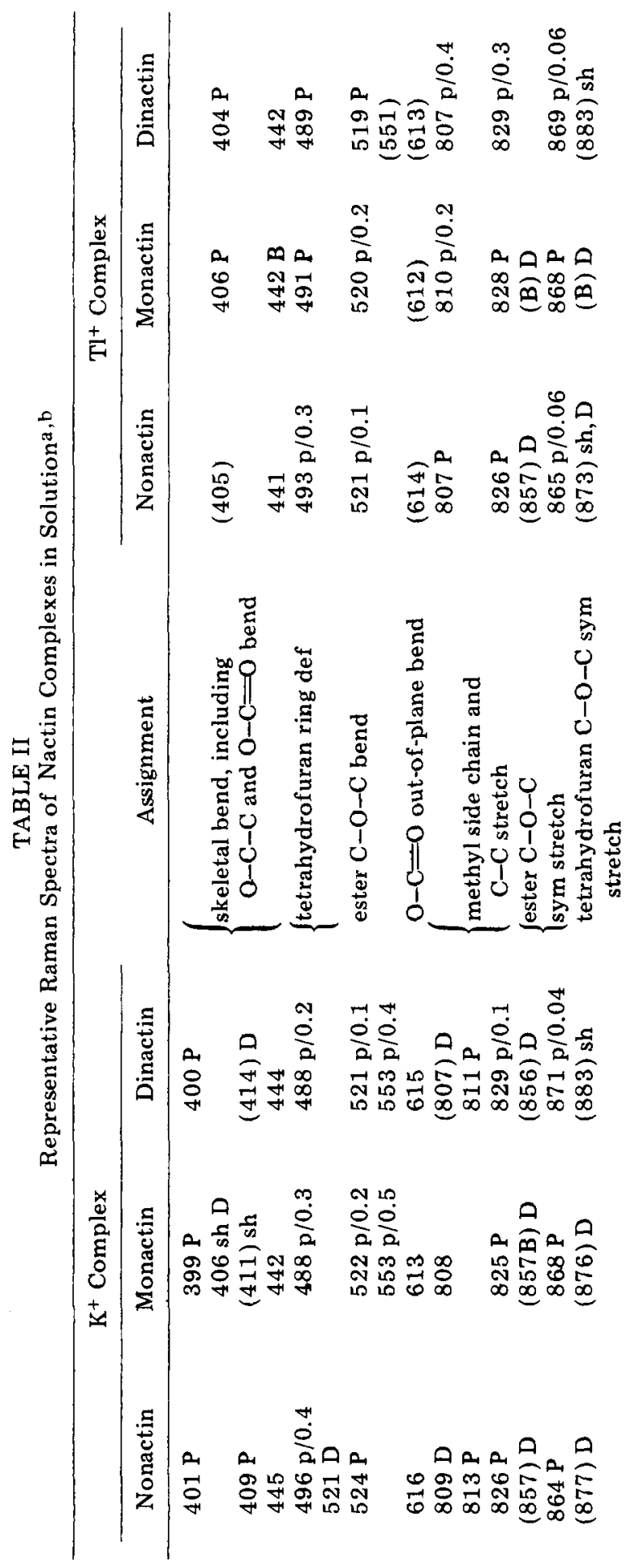




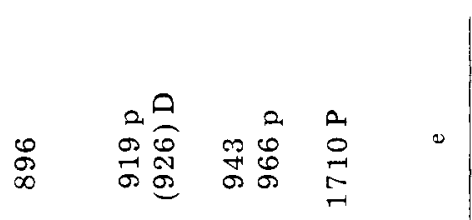

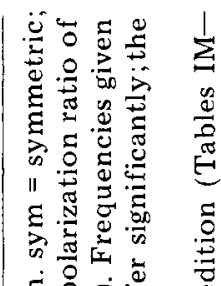

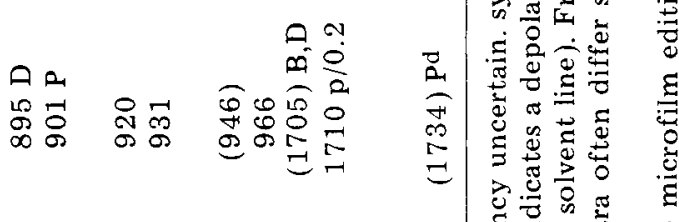

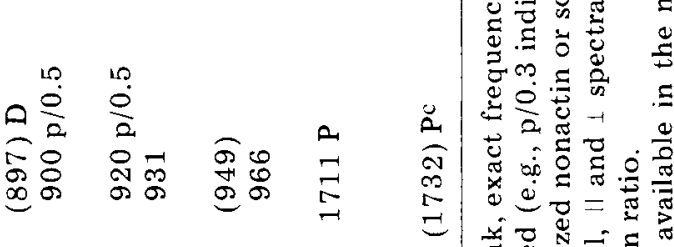

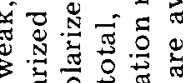

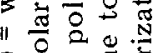

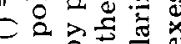

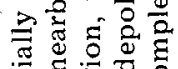

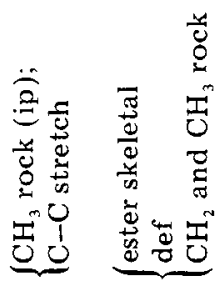

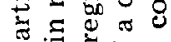

2.

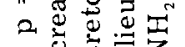

है

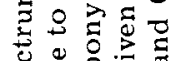

है

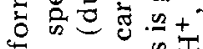

亲

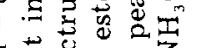

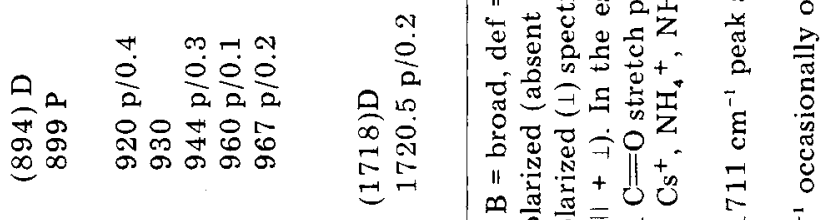

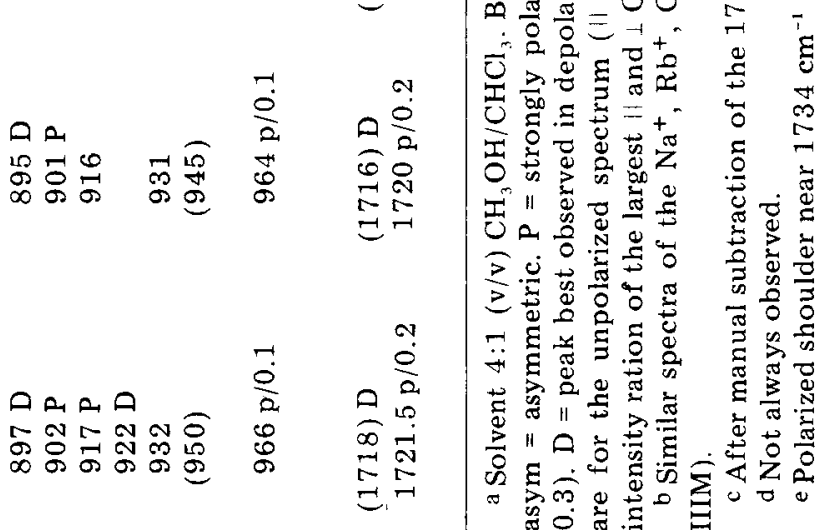


complexes, but not their spectra (except by adding anion peaks). Complexes of the nonspherical $\mathrm{NH}_{3} \mathrm{OH}^{+}$and $\mathrm{C}\left(\mathrm{NH}_{2}\right)_{3}{ }^{+}$ions were included to help distinguish between steric and electrostatic effects. ${ }^{12,13}$

Samples of uncomplexed nactins could be stored indefinitely, but powders and solutions of some nactin complexes often exhibited spectral changes after storage at $4^{\circ} \mathrm{C}$ (cf. Appendix).

The model compounds 2,5-dimethyl tetrahydrofuran and ethyl acetate were used to help identify tetrahydrofuran and ester carbonyl vibrations, respectively. Additional information was obtained from samples of nonactinic acid and its diester (acetyl, methyl) derivative, which were kindly provided by Prof. G. Büchi (Department of Chemistry, M.I.T.).

\section{RESULTS: SOLUTION SPECTRA}

Our data are presented in Tables IM-IIIM; typical spectra are displayed in Figures 2-4 (nonactin), Figure 5 (monactin and dinactin), and Tables II and III. Our discussion of the data is organized by spectral region.

\section{$400-650 \mathrm{~cm}^{-1}$ Region}

The spectra of the uncomplexed nactins in solution all show a weak, broad, unresolved band near $495 \mathrm{~cm}^{-1}$, with a peak near $520 \mathrm{~cm}^{-1}(\sim 521$, $517,515 \mathrm{~cm}^{-1}$ in nonactin, monactin, and dinactin, respectively) of comparable intensity. Complexation greatly enhances the intensity of the peak near $520 \mathrm{~cm}^{-1}$, which becomes one of the most prominent features of the spectrum (Figs. 2-5). In the $\mathrm{Tl}^{+}$complexes, the polarization ratio $\rho$ of the $520 \mathrm{~cm}^{-1}$ peak is substantially lower $(0<\rho<0.1)$ than in the other complexes $(\rho \sim 0.2)$.

In the monovalent cation complexes, the frequency of the $520 \mathrm{~cm}^{-1}$ peak decreases almost linearly with increasing ionic radius $R$, the only exception being the bulky $\mathrm{C}\left(\mathrm{NH}_{2}\right)_{3}{ }^{+}$ion. In the dinactin and monactin complexes, these frequencies are typically lower than in nonactin (Tables II, IM-IIIM). This region of the spectrum has been suggested ${ }^{9,14-16}$ to contain $\mathrm{C}-\mathrm{O}-\mathrm{C}$ bend vibrations of ether and ester groups. The assignment to ester vibrations is supported by the dramatic change in the intensity of the 520 $\mathrm{cm}^{-1}$ peak upon complexation and by its sensitivity to substitution at the ${ }^{11} \mathrm{C}$ position.

The broad $502 \mathrm{~cm}^{-1}$ band of uncomplexed nonactin shifts to $495 \mathrm{~cm}^{-1}$ upon complexation (except in the $\mathrm{Na}^{+}$complex in which it remains near $502 \mathrm{~cm}^{-1}$ as a broad shoulder on the intense $526 \mathrm{~cm}^{-1}$ peak). The $502 \mathrm{~cm}^{-1}$ peak is moderately polarized in nonactin $(\rho \sim 0.4)$ and its monovalent complexes $(0.3<\rho<0.5)$. The frequency of this band is systematically lower in monactin complexes $\left(487-493 \mathrm{~cm}^{-1}\right)$ and dinactin complexes $\left(488-489 \mathrm{~cm}^{-1}\right)$. The $\mathrm{Tl}^{+}$complex bands have the lowest polarization ratios.

Upon complexation, additional weak nactin bands are usually observed 


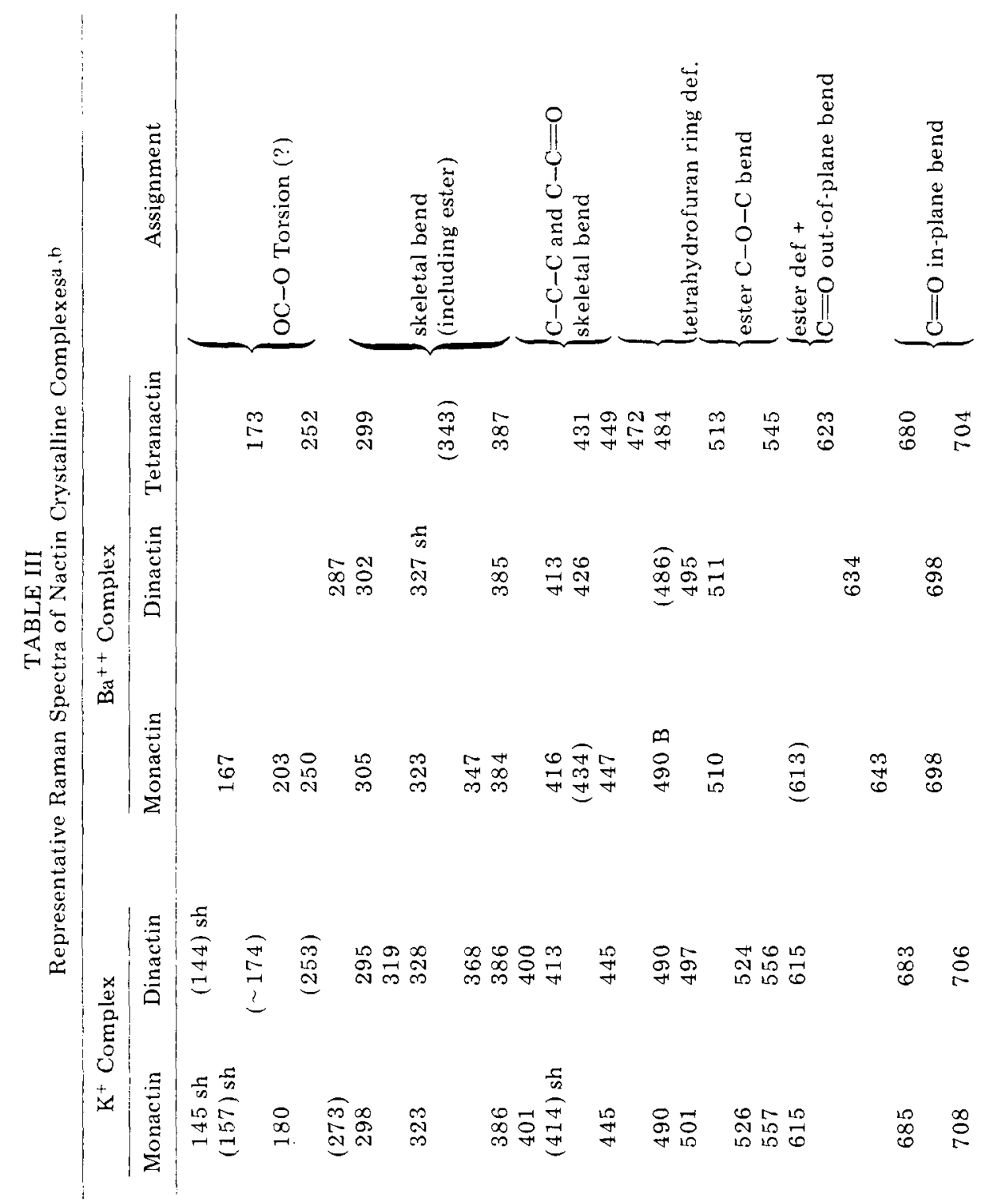




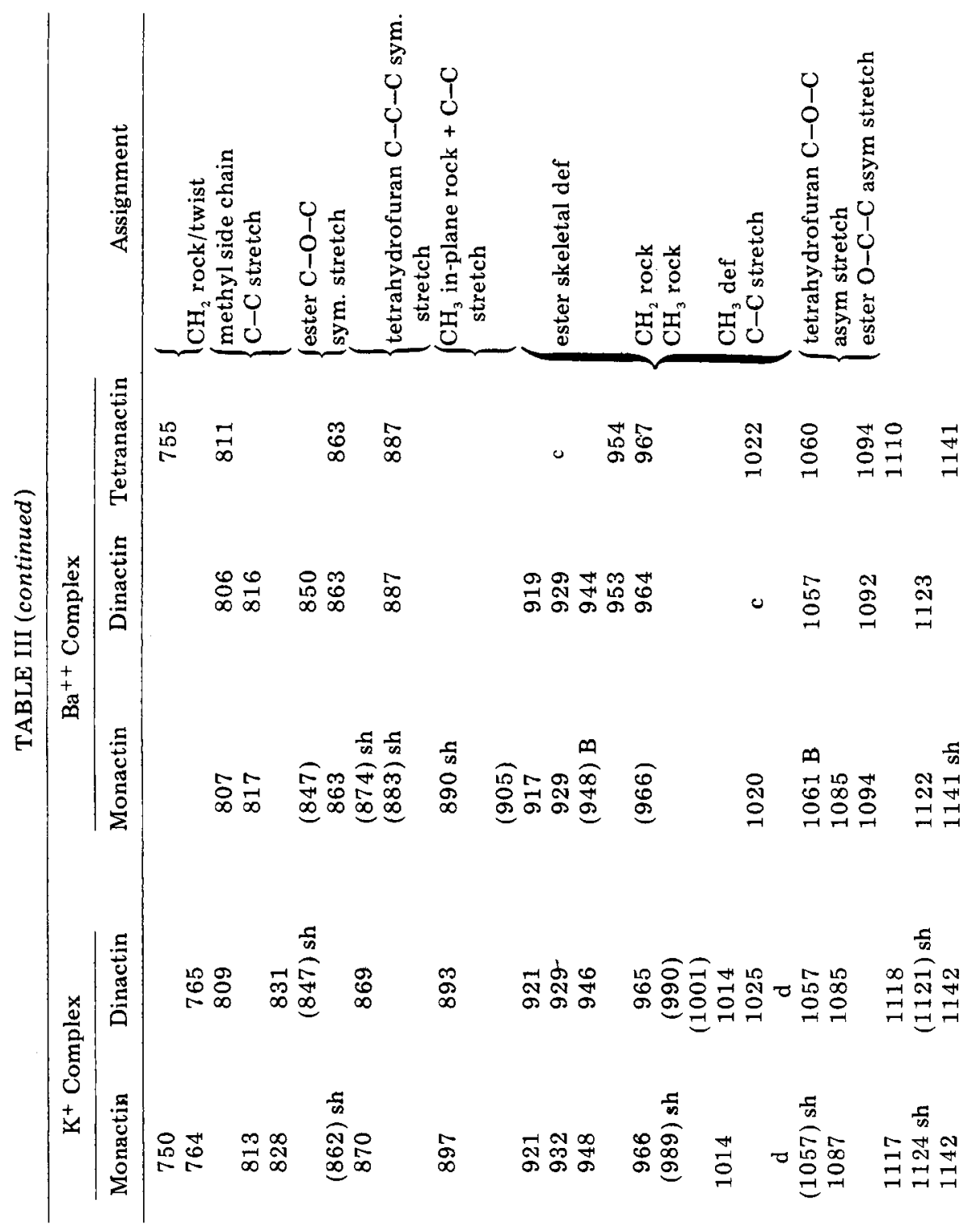




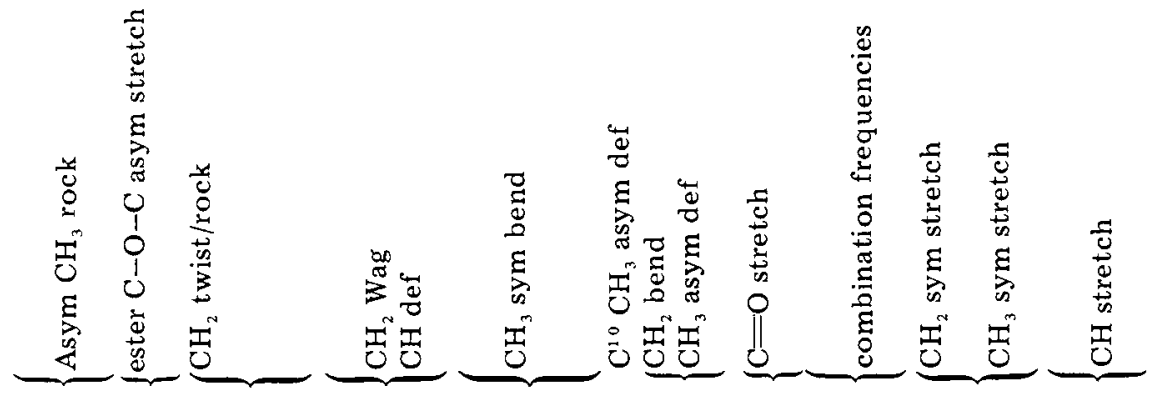

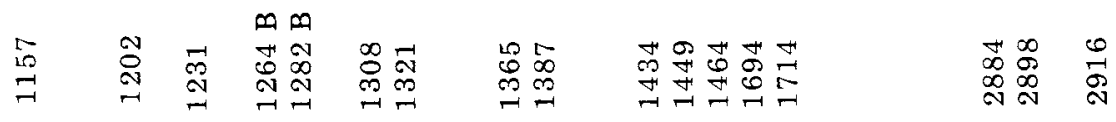

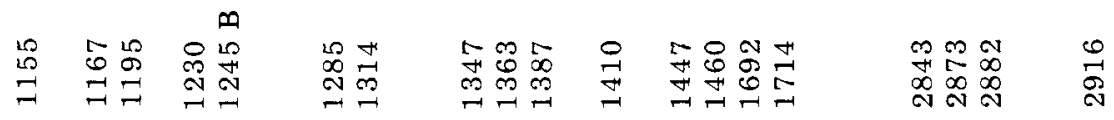

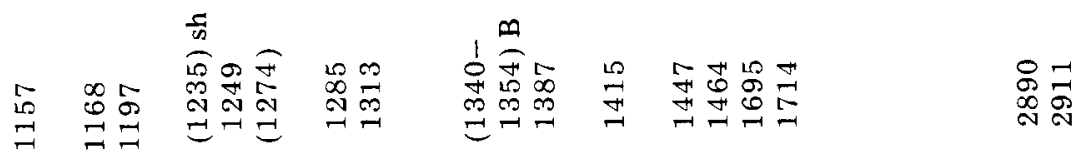

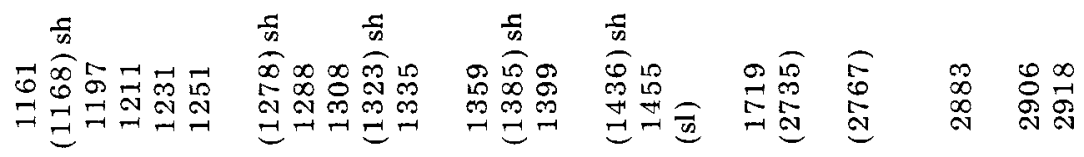

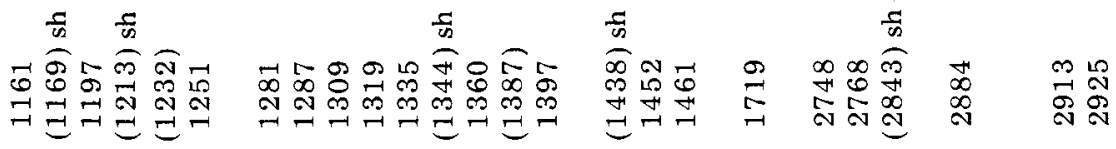




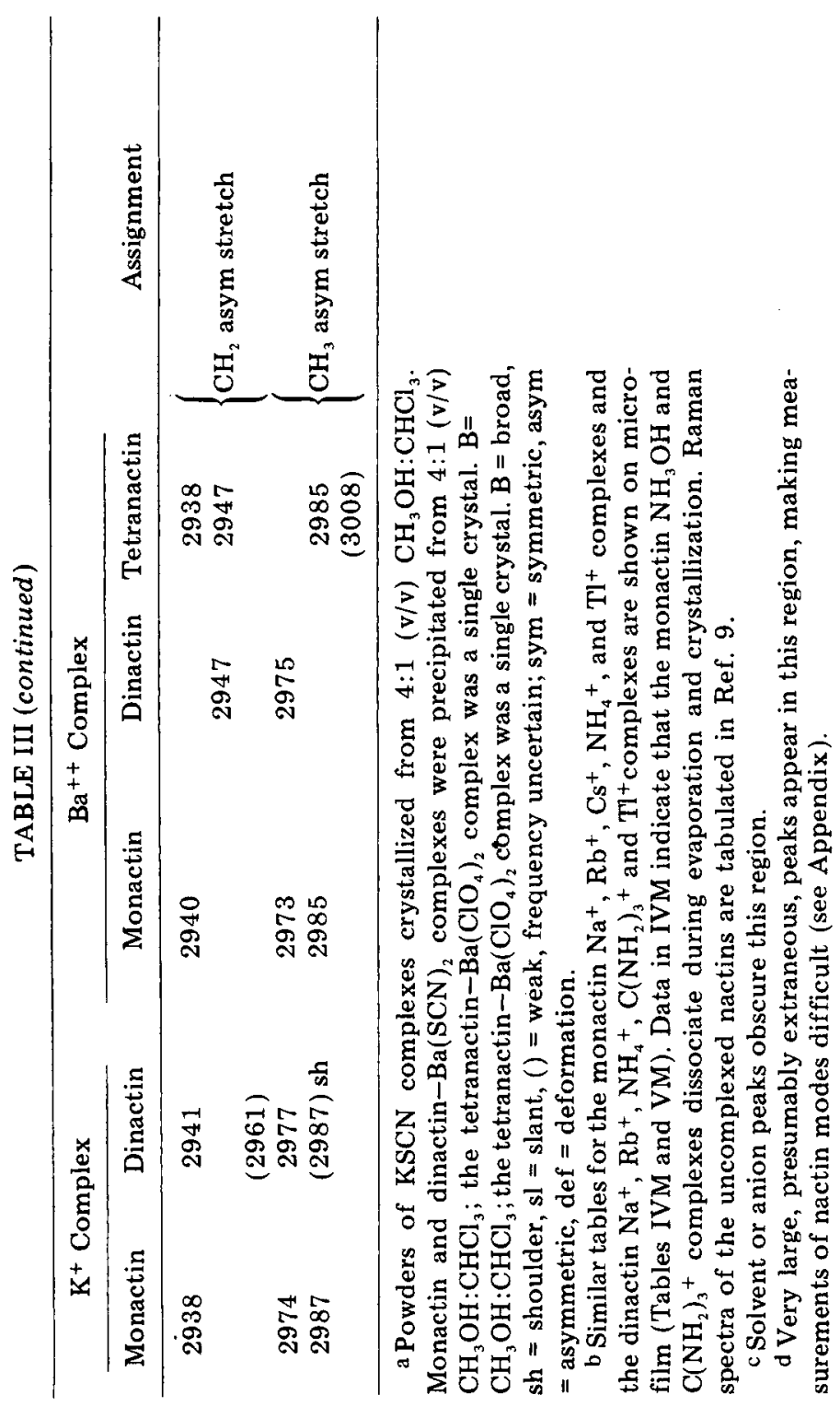


near $405,445,615$, and (in the higher nactins) $555 \mathrm{~cm}^{-1}$; the $405 \mathrm{~cm}^{-1}$ band is not observed in $\mathrm{Na}^{+}$complexes. The exact frequency of the $405 \mathrm{~cm}^{-1}$ band is difficult to measure due to interference from the neighboring solvent peak, but it appears to increase in the series $\mathrm{K}^{+}<\mathrm{Rb}^{+}<\mathrm{Cs}^{+}<\mathrm{NH}_{4}{ }^{+}<$ $\mathrm{C}\left(\mathrm{NH}_{2}\right)_{3}{ }^{+}$. The band is highly polarized in all nactins $(0<\rho<0.1)$, but an additional depolarized component appears $\sim 5 \mathrm{~cm}^{-1}$ higher in the $\perp$ spectra of some nactin complexes.

The unresolved singlet observed near $443 \mathrm{~cm}^{-1}$ in the $\mathrm{K}^{+}, \mathrm{Rb}^{+}, \mathrm{Cs}^{+}$ complexes can be decomposed into a polarized $\left(\sim 440 \mathrm{~cm}^{-1}\right)$ and depolarized $\left(\sim 447 \mathrm{~cm}^{-1}\right)$ doublet in some nactin $\mathrm{NH}_{4}{ }^{+}, \mathrm{NH}_{3} \mathrm{OH}^{+}$, and $\mathrm{C}\left(\mathrm{NH}_{2}\right)_{3}{ }^{+}$ complexes. Normal mode calculations on aliphatic polyesters ${ }^{15}$ predict $\mathrm{O}-\mathrm{C}=\mathrm{O}$ bending vibrations near $430-460 \mathrm{~cm}^{-1}$; ethyl acetate has a weak peak near $442 \mathrm{~cm}^{-1}$. This mode and the neighboring $405-410 \mathrm{~cm}^{-1}$ band could also represent $\mathrm{O}-\mathrm{C}-\mathrm{C}$ skeletal bend. ${ }^{15}$ The $443 \mathrm{~cm}^{-1}$ band is too weak to be observed in the uncomplexed nactins, which is consistent with the observed enhancement of the intensity of the other ester peaks ( 520 , $867,1720 \mathrm{~cm}^{-1}$ ) upon complexation.

Despite interference from an adjacent polarized solvent line, the depolarized peak near $615 \mathrm{~cm}^{-1}$ appears at approximately the same position in all of the nactin complexes. The $615 \mathrm{~cm}^{-1}$ peak is not observed in solutions of uncomplexed nonactin or monactin (it appears as a weak shoulder in uncomplexed dinactin). It may correspond to ester carbonyl out-of-plane bending vibrations $\left(611 \mathrm{~cm}^{-1}\right.$ in ethyl acetate), although a weak $613 \mathrm{~cm}^{-1}$ shoulder appears in spectra of 2,5-dimethyltetrahydrofuran.

\section{$800-975 \mathrm{~cm}^{-1}$ Region}

In uncomplexed nonactin, this region is dominated by an intense, highly polarized doublet at $867,878 \mathrm{~cm}^{-1}$. In contrast, the $878 \mathrm{~cm}^{-1}$ peak of nactin complexes is very weak and depolarized while the intensity of the $\sim 867 \mathrm{~cm}^{-1}$ peak (which remains polarized) is greatly enhanced. An additional weak peak appears near $857 \mathrm{~cm}^{-1}$ in the complexes. Due to the intensity of the $867 \mathrm{~cm}^{-1}$ peak, the 857 and $878 \mathrm{~cm}^{-1}$ peaks can usually only be seen in the depolarized spectra (cf. Fig. 4(c); Tables IM-IIIM). (The $878 \mathrm{~cm}^{-1}$ shoulder is visible in unpolarized $(\|+\perp)$ spectra of most dinactin complexes.)

For a given nactin, the frequencies of the $867,878 \mathrm{~cm}^{-1}$ peaks are nearly independent of the complexed ion (being $\sim 1 \mathrm{~cm}^{-1}$ higher for the lighter alkali ions). As discussed in Ref. 9, these peaks probably correspond to ester and ether $\mathrm{C}-\mathrm{O}-\mathrm{C}$ symmetric stretch vibrations, respectively. The frequency of the $864 \mathrm{~cm}^{-1}$ peak of nonactin complexes increases to $\sim 868$ $\mathrm{cm}^{-1}$ for monactin and $869 \mathrm{~cm}^{-1}$ for dinactin.

Uncomplexed nactins display a faint band near $898 \mathrm{~cm}^{-1}$ which becomes appreciably more intense upon complexation. A single, depolarized peak is seen in spectra of the $\mathrm{Na}^{+}$complexes. A close doublet, composed of a strong polarized component (whose frequency decreases in the series 
nonactin-dinactin) and a weaker depolarized component $\left(\sim 3-5 \mathrm{~cm}^{-1}\right.$ lower in frequency) is seen in the other complexes. We previously ${ }^{9}$ assigned this vibration to coupled methyl in-plane rock/C-C stretch vibrations on the basis of previously published studies of hydrocarbon chains. ${ }^{17-19}$

Spectra of uncomplexed nonactin and monactin display a doublet near $922,931 \mathrm{~cm}^{-1}$. Upon complexation, the lower peak downshifts $\sim 2 \mathrm{~cm}^{-1}$ in most complexes; its frequency is consistently lower for $\mathrm{Na}^{+}, \mathrm{K}^{+}$, and $\mathrm{Rb}^{+}$ than for the other ions. Upon complexation, the $931 \mathrm{~cm}^{-1}$ peak shifts up $\sim 1 \mathrm{~cm}^{-1}$ in nonactin and down $\sim 1 \mathrm{~cm}^{-1}$ in monactin. In contrast, uncomplexed dinactin displays a singlet near $925 \mathrm{~cm}^{-1}$, which shifts to 921 $\mathrm{cm}^{-1}$ upon complexation. Some dinactin complexes also show a weak shoulder near $931 \mathrm{~cm}^{-1}$. These modes may represent coupled ester skeletal deformation and $\mathrm{CH}_{3}$ rock, as does the $922,944 \mathrm{~cm}^{-1}$ doublet of ethyl acetate.

There is a weak polarized peak near $970 \mathrm{~cm}^{-1}$ in spectra of the uncomplexed nactins, assigned previously ${ }^{9}$ to combined methyl rock, $\mathrm{C}-\mathrm{C}$ stretch, and/or skeletal deformation. A similar peak appears near $966 \mathrm{~cm}^{-1}$ in spectra of nactin complexes.

\section{$1700-1750 \mathrm{~cm}^{-1}$ Region}

This spectral region contains the ester carbonyl stretch frequency. ${ }^{20,21}$ In previous notes, ${ }^{12,13}$ we have shown that the frequency of this vibration is particularly sensitive to details of the interactions between ester carbonyl groups and complexed cations. Since there are several ester carbonyl groups, there will be several ester carbonyl stretch modes, some of which may be degenerate in frequency. If the carbonyl groups are arranged around the cation in a tetrahedron, as is seen in X-ray crystallographic data, ${ }^{5-8}$ the local symmetry around the cation will be $T_{d}$. From the usual symmetry rules, ${ }^{22}$ the nine atoms in this local group (four $\mathrm{C}$, four $\mathrm{O}$, one cation) will contribute a total of nine modes: two $A_{1}$ modes, two $E$ modes (doubly degenerate), one $F_{1}$ mode (triply degenerate), and four $F_{2}$ modes (triply degenerate). The $A_{1}, E$, and $F_{2}$ modes are Raman active (the $A_{1}$ modes being polarized); only the $F_{2}$ modes are infrared active. The $\mathrm{C}=\mathrm{O}$ and $\mathrm{O}$. . cation stretch coordinates give rise to eight spectral lines; by comparison with the normal modes of $\mathrm{CH}_{4}$, these are seen to be the two $A_{1}$ modes and two triply degenerate $F_{2}$ modes. In one $A_{1}$ mode and one triply degenerate $F_{2}$ mode, $\mathrm{C}=\mathrm{O}$ stretch will dominate, leading to spectral lines in the $1700 \mathrm{~cm}^{-1}$ region. In the other two modes, low-frequency $(<500$ $\mathrm{cm}^{-1}$ ) $\mathrm{O}$. . .cation stretch dominates; such modes have been observed in the infrared spectrum of valinomycin. ${ }^{23}$

In uncomplexed nonactin, the carbonyl stretch peak appears as a single broad band near $1725 \mathrm{~cm}^{-1}$, which is seen in the polarized spectrum as a $1732 \mathrm{~cm}^{-1}$ band (with a $1716 \mathrm{~cm}^{-1}$ shoulder) and in the depolarized spectrum as a $1720,1733 \mathrm{~cm}^{-1}$ doublet. A broad polarized doublet appears near $1718,1732 \mathrm{~cm}^{-1}$ in spectra of uncomplexed monactin and dinactin. The 
splitting of the polarized and unpolarized peaks may arise from hydrogen bonding to the solvent; that hydrogen bonding reduces carbonyl stretch frequencies has previously been observed in simple esters ${ }^{24}$ and depsipeptides. ${ }^{25,26}$

Upon complexation with ions other than $\mathrm{Na}^{+}$and $\mathrm{Tl}^{+}$, the broad band seen in the uncomplexed nactins near $1725 \mathrm{~cm}^{-1}$ sharpens into an intense, highly polarized peak with a depolarized shoulder located $2-5 \mathrm{~cm}^{-1}$ lower in frequency. The intensity of the depolarized shoulder is $\sim 1 / 5$ that of the polarized peak. The polarized component corresponds to the fully symmetric stretch $A_{1}$ mode (i.e., all four carbonyl groups stretching in phase) while the depolarized line corresponds to the $F_{2}$ mode. As discussed below, the $A_{1}$ mode is the most useful for studies of the antibiotic-cation interaction.

The nactin- $\mathrm{Na}^{+}$complexes are the only ones to display a distinct doublet $\left(\sim 1720,1730 \mathrm{~cm}^{-1}\right)$ in the unpolarized $(\|+\perp)$ spectrum. The shape of this peak might at first suggest that some free nactin is present; however, spectra taken in $0.5 \mathrm{M}$ and $2.0 \mathrm{M}$ NaSCN have the same line shape, indicating that the nactin molecules are all complexed. The $1720 \mathrm{~cm}^{-1}$ peak is depolarized; the 1730 peak is polarized and, therefore, corresponds to the symmetric $A_{1}$ mode.

Unlike complexes with other ions, the nactin- $\mathrm{Tl}^{+}$complex shows a single, intense, highly polarized peak at an exceptionally low frequency $(\sim 1710$ $\mathrm{cm}^{-1}$ ). There is no depolarized component (except perhaps near $1705 \mathrm{~cm}^{-1}$ in the monactin complex), but there is a weak, polarized band near 1735 $\mathrm{cm}^{-1}$.

Additional weak polarized peaks appear near $1705 \mathrm{~cm}^{-1}$ in the $\mathrm{NH}_{4}{ }^{+}$ and $\mathrm{C}\left(\mathrm{NH}_{2}\right)_{3}{ }^{+}$complexes, except in dinactin- $\mathrm{C}\left(\mathrm{NH}_{2}\right)_{3}{ }^{+}$(in which it appears near $1714 \mathrm{~cm}^{-1}$ ).

\section{SOLID-STATE SPECTRA}

Raman spectra were obtained of crystalline cation complexes of monactin and dinactin. These were obtained by evaporating to dryness nactin solutions containing an excess of salt. Our data are presented in Tables III, IVM, and VM. Typical Raman spectra are presented in Table III and Figures 6 and 7. Efforts to crystallize nactin- $\mathrm{NH}_{3} \mathrm{OHCl}$ complexes produced samples whose spectra closely resemble those of the uncomplexed nactins [compare Figs. 6(a) and 7(b)]. Apparently, the forces which stabilize the nactin- $\mathrm{NH}_{3} \mathrm{OH}^{+}$complex in solution do not effectively compete with the interactions which stabilize the $\mathrm{NH}_{3} \mathrm{OHCl}$ and uncomplexed nactin crystal lattices. Similarly, solid-state samples of the dinactin- $\mathrm{CsCl}$ and the monactin- $\mathrm{C}\left(\mathrm{NH}_{2}\right)_{3} \mathrm{Cl}$ complexes could not be obtained.

In general, the Raman spectra of the crystalline complexes show considerably more detail than the solution spectra because: 1) no spectral regions are obscured by solvent lines; 2) the peaks are narrower than in solution spectra, permitting more detailed observation of substructure; and 


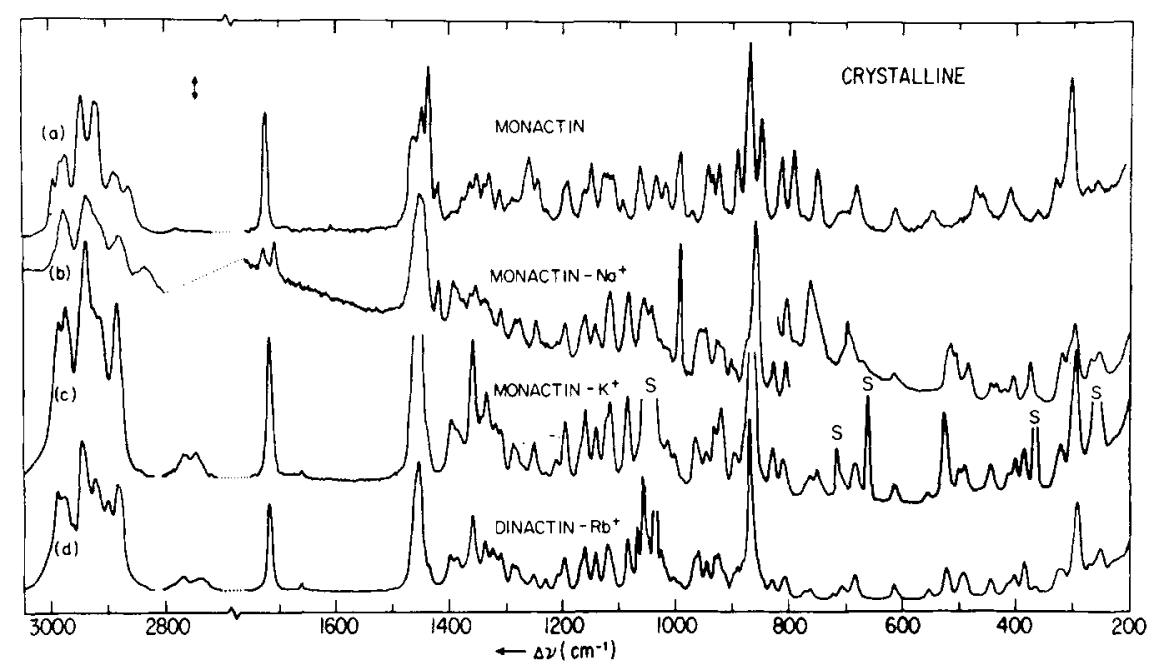

Fig. 6. Raman spectra of (a) crystalline monactin, (b) the monactin- $\mathrm{Na}^{+}$complex, (c) the monactin- $\mathrm{K}^{+}$complex, and (d) the dinactin- $\mathrm{Rb}^{+}$complex. The nactin complexes were obtained by total evaporation of solutions containing an excess of salt. "S" denotes a residual solvent peak. Vertical arrow represents (a), (c) 100 counts/sec, (b), (d) 300 counts $/ \mathrm{sec}$, except between $2800-3100 \mathrm{~cm}^{-1}$ where (a), (c) 300 counts $/ \mathrm{sec}$, (b), (d), 1000 counts $/ \mathrm{sec}$. Scanning speed $30 \mathrm{~cm}^{-1} / \mathrm{min}$, slit width $\sim 4 \mathrm{~cm}^{-1}$, incident power (a) $90 \mathrm{~mW}$, (b) $\sim 40 \mathrm{~mW}$, incident wavelength (a), (b) $5145 \AA$, (c), (d) $4579 \AA$.

3) contact forces between adjoining molecules in the solid cause frequency shifts and line splittings.

For example, in the different complexes, the deformation modes of the tetrahydrofuran ring (near $490 \mathrm{~cm}^{-1}$ in solution) are differently affected by crystallization. The singlets observed in solutions of monactin- $\mathrm{K}^{+}$, $\mathrm{C}\left(\mathrm{NH}_{2}\right)_{3}{ }^{+}$are split into doublets $\left(\sim 12 \mathrm{~cm}^{-1}\right.$ separation $)$ in the solid state. The $\sim 490 \mathrm{~cm}^{-1}$ peak of the $\mathrm{Na}^{+}$complexes shifts $\sim 5 \mathrm{~cm}^{-1}$ downward, while that of the dinactin- $\mathrm{Rb}^{+}, \mathrm{Tl}^{+}$complexes shifts $\sim 4 \mathrm{~cm}^{-1}$ upward. Similarly, the $\sim 440 \mathrm{~cm}^{-1}$ bands of the $\mathrm{Na}^{+}$complexes [Figs. 5(b) and 5(e)] are split into clearly resolved doublets in the solid state (Fig. 6(b), Table IVM).

The ester deformation band seen near $522 \mathrm{~cm}^{-1}$ in nactin solutions is downshifted considerably in crystalline dinactin- $\mathrm{Na}^{+}$, monactin- $\mathrm{Na}^{+}$, and monactin- $\mathrm{Cs}^{+}\left(15,8,5 \mathrm{~cm}^{-1}\right.$, respectively). In the other crystalline complexes, the solid-state frequencies of this mode are shifted upward 2-5 $\mathrm{cm}^{-1}$. Similarly, the peak near $932 \mathrm{~cm}^{-1}$, which may represent ester skeletal deformations, is shifted downward only in the crystalline dinactin- $\mathrm{Na}^{+}$, and monactin- $\mathrm{Na}^{+}$, monactin- $\mathrm{C}\left(\mathrm{NH}_{2}\right)_{3}{ }^{+}$, and monactin-Cs ${ }^{+}$ complexes. These results, and the anomalously high carbonyl stretch frequency of the crystalline monactin-Cs ${ }^{+}$complex (upshifted $4 \mathrm{~cm}^{-1}$ ) suggest that crystallization may slightly affect the structure of some complexes.

Other anomalies are observed for the largest and smallest cations. For example, the dinactin- $\mathrm{C}\left(\mathrm{NH}_{2}\right)_{3}{ }^{+}$complex is characterized by the absence of a $444 \mathrm{~cm}^{-1}$ peak, a $7 \mathrm{~cm}^{-1}$ downshift in the $385 \mathrm{~cm}^{-1}$ peak, and the co- 


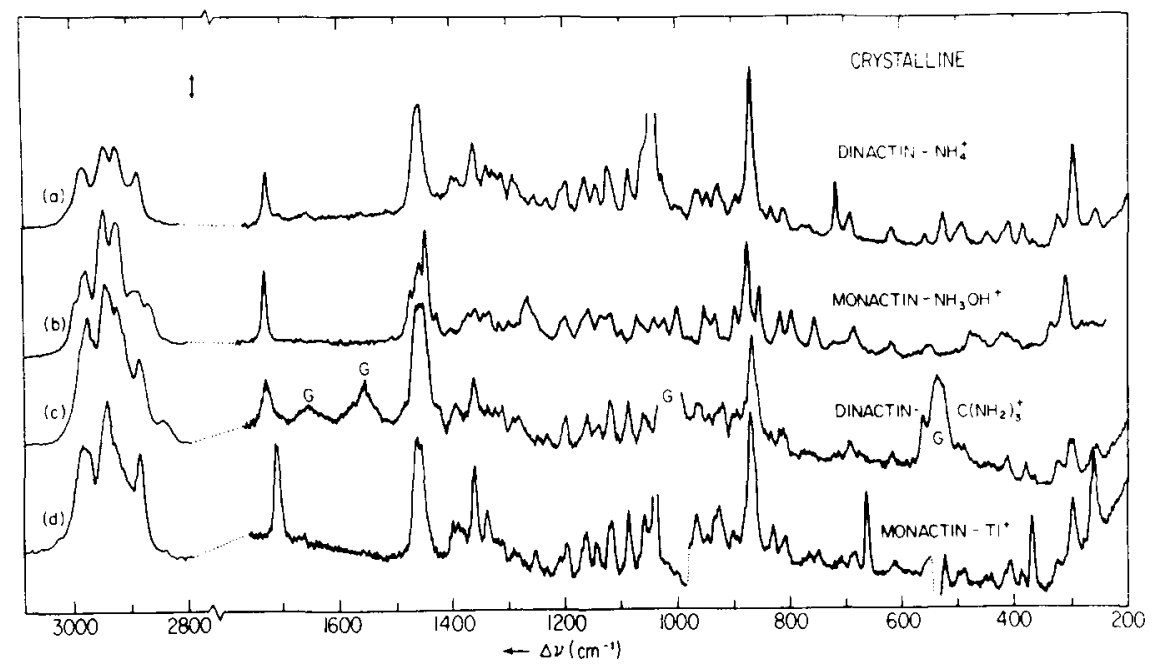

Fig. 7. Raman spectra of crystalline (a) dinactin $-\mathrm{NH}_{4}{ }^{+}$complex, (b) monactin crystallized from a solution containing a tenfold excess of $\mathrm{NH}_{3} \mathrm{OHCl}$ (uncomplexed), (c) dinactin$\mathrm{C}\left(\mathrm{NH}_{2}\right) 3^{+}$complex, and (d) monactin- $\mathrm{Tl}^{+}$complex. Vertical arrow represents 100 counts/sec, except between $2800-3100 \mathrm{~cm}^{-1}(300)$. Scanning speed $30 \mathrm{~cm}^{-1} / \mathrm{min}$, slit width $\sim 4 \mathrm{~cm}^{-1}$, incident power (a), (b) $\sim 40 \mathrm{~mW}$, (c), (d) $\sim 100 \mathrm{~mW}$, incident wavelength (a) $5145 \AA$, (b), (c) $4880 \AA$, (d) $4579 \AA$. The monactin- $\mathrm{NH}_{3} \mathrm{OHCl}$ complex dissociated upon crystallization. Guanidinium peaks are denoted by $\mathrm{G}$.

alescence of the doublet near, $1394 \mathrm{~cm}^{-1}$. Similarly, solid-state samples of dinactin- $\mathrm{Cs}^{+}$, dinactin- $\mathrm{C}\left(\mathrm{NH}_{2}\right)_{3}{ }^{+}$and monactin or dinactin- $\mathrm{NH}_{3} \mathrm{OH}^{+}$ could not be obtained.

Pronounced crystalline effects are also seen in the carbonyl stretch region. The unresolved $1720,1729 \mathrm{~cm}^{-1}$ doublet of the monactin- $\mathrm{Na}^{+}$complex in solution [Fig. 5(b)] is split into a distinct $1708,1727 \mathrm{~cm}^{-1}$ doublet in the solid state. A close $1720,1729 \mathrm{~cm}^{-1}$ doublet of the dinactin- $\mathrm{Na}^{+}$complex is similarly resolved $\left(1709,1733 \mathrm{~cm}^{-1}\right)$ in the solid state (Tables IIIM and VM). Upon crystallization, the carbonyl stretch frequencies $\nu_{\mathrm{CO}}$ of the monactin- $\mathrm{Rb}^{+}, \mathrm{Cs}^{+}$, and $\mathrm{Tl}^{+}$complexes shift $-3,+4,-1.5 \mathrm{~cm}^{-1}$, respectively; those of the dinactin- $\mathrm{K}^{+}, \mathrm{Rb}^{+}$, and $\mathrm{Tl}^{+}$complexes shift $-1.5,-1.5$, $-2 \mathrm{~cm}^{-1}$, respectively. In all other cases in which the comparison can be made, $\nu_{\mathrm{CO}}$ is shifted $1 \mathrm{~cm}^{-1}$ or less downward. As in solution, $\nu_{\mathrm{CO}}$ is apparently the same for both monactin and dinactin complexes (Fig. 12).

Although the $\mathrm{CH}_{2}, \mathrm{CH}_{3}$ stretch region $\left(2800-3000 \mathrm{~cm}^{-1}\right)$ of the uncomplexed nactins was found to be sensitive to crystal packing, ${ }^{9}$ it is essentially the same for all the crystalline complexes except $\mathrm{NH}_{4}{ }^{+}$, in which the 2923 , $2942 \mathrm{~cm}^{-1}$ peaks are of equal intensity [Fig. 7(a)]. However, the nactin$\mathrm{NH}_{4}{ }^{+}$samples are fully complexed; notice, for example, that they lack the $\sim 2866,2884 \mathrm{~cm}^{-1}$ doublet seen in the uncomplexed solid-state mixture of monactin and $\mathrm{NH}_{3} \mathrm{OHCl}$ [Figs. 7(a) and (b)]. The $\mathrm{NH}_{4}{ }^{+}$complexes also lack the subtle substructure typical of this region in the other complexes.

On occasion, variable, intense lines appear near $1000-1050 \mathrm{~cm}^{-1}$ in 
spectra of crystalline dinactin complexes; they appear to be artifacts (see Appendix).

\section{DISCUSSION}

In general, two types of information may be obtained from our data. First, cation-dependent changes in the frequency and line shape of particular spectral lines may give information about cation-nactin interactions. In particular, the ester carbonyl stretch frequency $\left(\sim 1720 \mathrm{~cm}^{-1}\right)$ gives information about the cation-carbonyl interaction. Similarly, spectral changes can provide information about the interaction of nactin complexes with their environment (crystalline forces, solvents, etc.). Second, line shapes and polarization measurements can provide information about the conformation and symmetry of the nactin complex. Such data provide a test of isostericity - the assumption that the complexes of different cations are basically similar in conformation. Comparison of spectra taken in the solid state and in solution may indicate the extent to which X-ray diffraction studies on the crystalline complexes can be used to interpret the behavior of the nactins in solution.

\section{Nactin-Cation Interactions}

The symmetric ester carbonyl stretch mode (which may readily be distinguished from the other ester carbonyl stretching modes by its great intensity and complete polarization) is found to be a particularly useful probe of the cation-nactin carbonyl interaction. Since the carbonyl group is usually in close contact with the cation, one might expect that a force which causes the nactin ring to expand to accommodate a larger cation would perturb the carbonyl stretch mode. Such a perturbation might be expected to be proportional to the force distorting the nactin ring, and thus be simply related to the ionic radius of the enclosed cation. That is, although the primary nactin-cation interaction is electrostatic, differences in the interaction in different cation complexes could have a simple, steric explanation. This would suggest a simple dependence of the corresponding ester carbonyl stretch frequency $\nu_{\mathrm{CO}}$ on cationic radius $R$. Figure 8 plots $\nu_{\mathrm{CO}}$ as a function of $R$ for eight different cation complexes. For the polyatomic cations, $R$ is the average of the four N. . O distances, as taken from X-ray data $^{7}$ and simple models (Fig. 9). For the $\mathrm{Na}^{+}$and $\mathrm{K}^{+}$complexes, X-ray structural data give better values for the cation-oxygen distances than those afforded by the simple model; these values are indicated by the crosses in Figures 8 and 10.

As is seen in Figure 8, $\nu_{\mathrm{CO}}$ is not a simple function of $R$, at least for the polyatomic cations. In particular, the $\mathrm{Cs}^{+}, \mathrm{NH}_{3} \mathrm{OH}^{+}$, and $\mathrm{C}\left(\mathrm{NH}_{2}\right)_{3}{ }^{+}$ions have approximately the same average $\mathrm{Cs}^{+} \ldots \mathrm{O}$ or N. . O distances, but quite different stretch frequencies $\nu_{\mathrm{CO}}$. (While it is, of course, possible to change the definition of the average radius $R$, in order for $\nu_{\mathrm{CO}}$ of the 


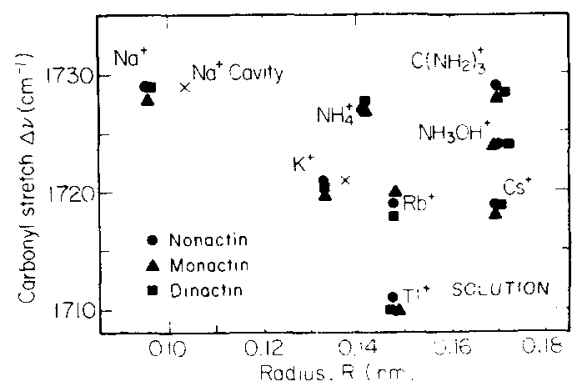

Fig. 8. Ester carbonyl stretch frequency $\nu_{\mathrm{CO}}$ as a function of ionic radius for complexes of nonactin (๑), monactin $(\triangleleft)$, and dinactin $(\bullet)$ in 4:1 (v/v) $\mathrm{CH}_{3} \mathrm{OH} / \mathrm{CHCl}_{3}$. For $\mathrm{Na}^{+}$and $\mathrm{K}^{+}$ complexes, the ionic radius and the cavity radius (as defined by the ion-oxygen distances) are not the same. The crosses indicate cavity radii (Refs. 5 and 8 ), Notice that the $\mathrm{Cs}^{+}$, $\mathrm{NH}_{3} \mathrm{OH}^{+}$, and $\mathrm{C}\left(\mathrm{NH}_{2}\right)_{3}$ complexes display different frequencies $\nu_{C}$ even though the ions are of similar size.

$\mathrm{C}\left(\mathrm{NH}_{2}\right)_{3}{ }^{+}$complexes to fit on the same curve as the alkali complexes, it would be necessary for the average radius of $\mathrm{C}\left(\mathrm{NH}_{2}\right)_{3}{ }^{+}$to be less than that of $\mathrm{K}^{+}$.)

A closer examination of Figure 8 indicates that $\nu_{\mathrm{CO}}$ for the monoatomic alkali cations depends approximately on $1 / R$. This suggests the possibility that $\nu_{\mathrm{CO}}$ is being perturbed by cation-nactin carbonyl electrostatic interactions, rather than by contact between cation and nactin carbonyl. This hypothesis is tested in Figure 10, which plots $\nu_{\mathrm{CO}}$ as a function of the electrostatic interaction energy $U$, as calculated from a simple model (Fig. 9). For most complexes, $\nu_{\mathrm{CO}}$ is proportional to $U$. Note, in particular, the position of the $\mathrm{Cs}^{+}, \mathrm{NH}_{3} \mathrm{OH}^{+}$, and $\mathrm{C}\left(\mathrm{NH}_{2}\right)_{3}{ }^{+}$complexes. These results indicate that the variation in the nactin-cation interaction between different cation complexes arises primarily from electrostatic, rather than steric, effects.

Some of the observed departures from the straight line of Figure $10 \mathrm{might}$ be expected. The extraction coefficients of $\mathrm{NH}_{4}{ }^{+}$and $\mathrm{Tl}^{+}$by nonactin (from an aqueous to a bulk organic phase) are anomalous. ${ }^{1,27}$ The $\mathrm{NH}_{4}{ }^{+}$ ion is known, at least in tetranactin, ${ }^{7}$ to hydrogen bond to the tetrahydrofuran rings. The nactin . . $\mathrm{Tl}^{+}$interaction may also contain a nonelectrostatic contribution, namely, partially covalent bonds between the $\mathrm{Tl}^{+}$ ion and the nactin carbonyl groups. ${ }^{27}$ Finally, X-ray crystallographic measurements ${ }^{6}$ on the nonactin- $\mathrm{Na}^{+}$complex show that steric interactions between the ester carbonyl oxygen atoms prevent them from coming in contact with the $\mathrm{Na}^{+}$. The small deviation $\left(\sim 1 \mathrm{~cm}^{-1}\right)$ for the large $\mathrm{Cs}^{+}$ cation may not be significant, since it is less than the uncertainty in the best position of the line (Fig. 10).

\section{Induction Effect}

The ionic selectivities of the five homologous nactins are not the same. Krasne and Eisenman have proposed ${ }^{27}$ that these differences may arise 

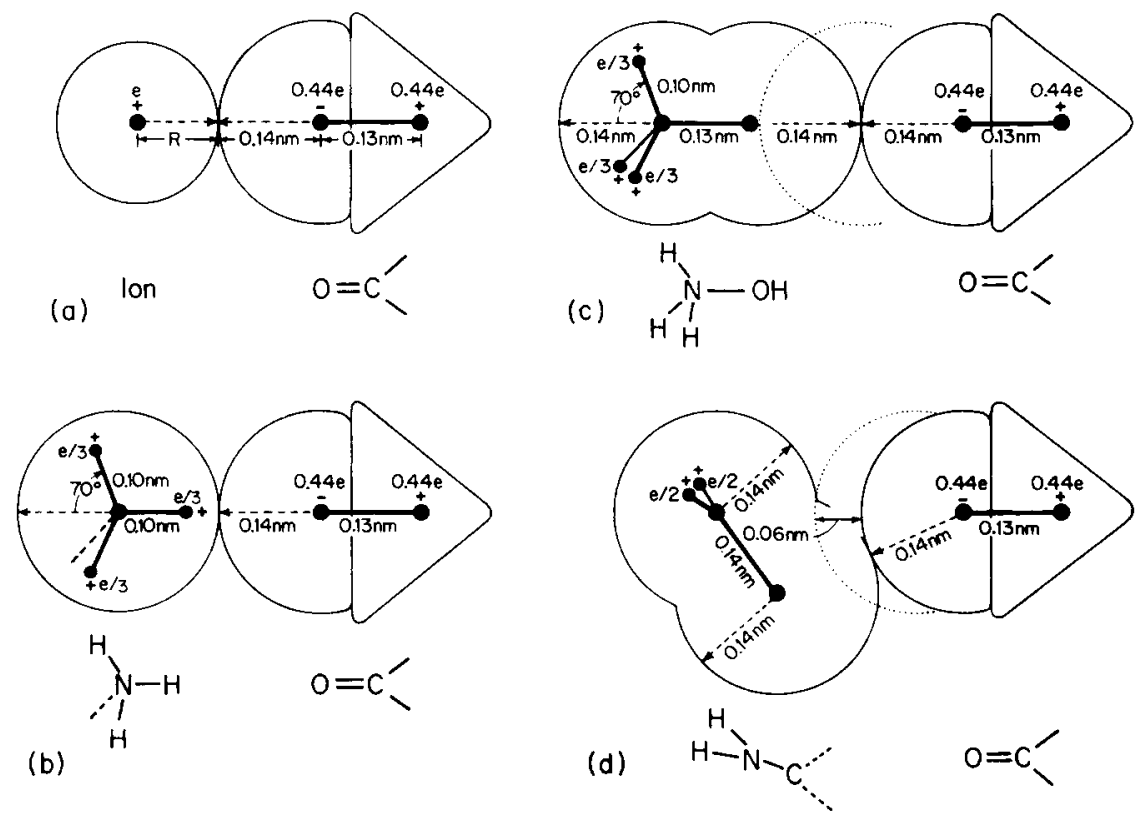

Fig. 9. (a) Model of Krasne and Eisenman ${ }^{27}$ for the ion-carbonyl electrostatic interaction, showing the edges of the ion (radius $R$ ) and the oxygen (radius $0.14 \mathrm{~nm}$ ) in contact. It is assumed that the nactin molecules are flexible and that the other ester carbonyl groups assume equivalent positions with respect to the cation. The indicated point charges are located at the nuclei (solid circles). The carbonyl charges are from the Krasne-Eisenman discussion of nonactin. (b) Modification of the Krasne-Eisenman model ${ }^{27}$ to describe the interaction of an ester carbonyl group with amine protons, as in the $\mathrm{NH}_{3} \mathrm{OH}^{+}$complex. In the $\mathrm{NH}_{3} \mathrm{OH}^{+}$ complex, one carbonyl group (c) interacts sterically with the hydroxyl group. The dotted circle indicates the position that the carbonyl group would take if the hydroxyl group were absent. In the $\mathrm{C}\left(\mathrm{NH}_{2}\right)_{3}{ }^{+}$complex, two carbonyl groups (d) interact sterically with the carbon atom of the cation; the dotted circle shows the position that the carbonyl oxygen would assume if the $\mathrm{C}\left(\mathrm{NH}_{2}\right)_{3}{ }^{+}$ion were absent. The other two carbonyl groups approach the hydrogens of one $\mathrm{NH}_{2}$ directly as in (b). The other $\mathrm{NH}_{2}$ groups of the $\mathrm{C}\left(\mathrm{NH}_{2}\right)_{3}{ }^{+}$cation extend into and out of the plane and are omitted for clarity. The electrostatic interaction energy $U$ for the $\mathrm{NH}_{3} \mathrm{OH}^{+}$and $\mathrm{C}\left(\mathrm{NH}_{2}\right)_{3}{ }^{+}$complexes was calculated for the sterically unhindered carbonyl groups (b) using the fractional charges shown in (c) and (d), respectively.

because the inductive effect of the additional ethyl groups in the higher nactins (cf. Fig. 1) increases the effective charge on the neighboring carbonyl groups. If $\nu_{\mathrm{CO}}$ is sensitive to the electrostatic interaction energy $U$ (as it appears to be), comparison of our measurements on nonactin, monactin, and dinactin may be used to test this proposal. In the higher nactins, an increase in the average charge separation would increase $U$ for the affected carbonyl groups, leading either to a line splitting (if the effect were large enough) or to an increase in the average $\nu_{\mathrm{CO}}$.

Such effects are not seen. The carbonyl stretch peaks of monactin and dinactin complexes in solution (Fig. 5) are the same width as those of nonactin (Figs. 2-4). The values of $\nu_{\mathrm{CO}}$ for the three nactins are almost 


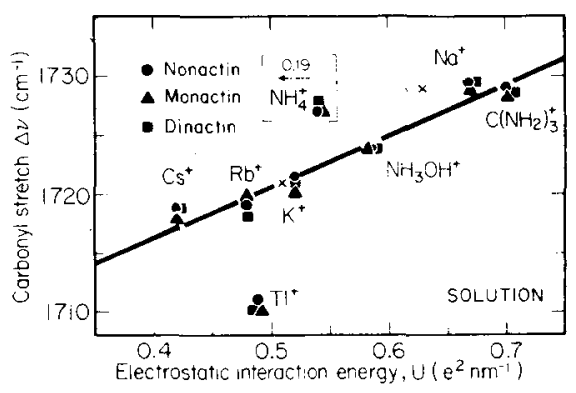

Fig. 10. Ester carbonyl stretch frequency $\nu_{C O}$ as a function of electrostatic interaction energy I for nonactin $(\bullet)$, monactin $(\Delta)$, and dinactin $(\square)$ complexes in $4: 1(\mathrm{v} / \mathrm{v}) \mathrm{CH}_{3} \mathrm{OH} / \mathrm{CHCl}_{3}$. $Y$ is calculated by Coulomb's law for the charges and positions shown in figure 9 , supplemented by available $\mathrm{X}$-ray structural data. Crosses indicate values of $U$ calculated with the aid of $\mathrm{X}$-ray data rather than the simpler model of Figure 9. Compare the positions of the $\mathrm{Cs}^{+}$, $\mathrm{NH}_{3} \mathrm{OH}^{+}$, and $\mathrm{C}\left(\mathrm{NH}_{2}\right)_{3}{ }^{+}$ions with those of Figure 8. Atomic coordinates obtained from X-ray diffraction, when combined with the formal charges of Figure $10(\mathrm{~b})$, give a value $U=0.19$ for the tetranactin- $\mathrm{NH}_{4}{ }^{+}$complex.

identical (Fig. 10), and no systematic differences leading to a change of slope are seen. Although the average value of $\nu_{\mathrm{CO}}$ for monovalent nonactin complexes is $\sim 0.6 \mathrm{~cm}^{-1}$ higher than for monactin or dinactin, this would correspond (Fig. 10) to a $\sim 3 \%$ reduction in the average electrostatic interaction energy $U$, which is the opposite of the effect suggested by Krasne and Eisenman. ${ }^{27}$ The observed reduction in $\nu_{\mathrm{CO}}$ could arise from changing the effective mass of the nactin molecule near the ester group (caused by replacement of methyl with ethyl groups). Furthermore, effective mass and inductive effects could fortuitously cancel.

Data for the crystalline complexes (Fig. 11) are similar to those found in solution (Fig. 10), except that the $\mathrm{Cs}^{+}$complex lies off the line defined by the $\mathrm{Rb}^{+}, \mathrm{K}^{+}, \mathrm{NH}_{3} \mathrm{OH}^{+}$, and $\mathrm{C}\left(\mathrm{NH}_{2}\right)_{3}{ }^{+}$ions. It is interesting that the line for the crystalline complexes has the same slope as the line for the solutions. This suggests that crystal interactions have about the same effect on $\nu^{\prime} \circ$ in all of these complexes.

\section{Other Spectral Regions}

Although the $\sim 920 \mathrm{~cm}^{-1}$ (skeletal deformation) peaks of the nonactin and monactin complexes undergo a considerable change in intensity upon complexation, their frequencies increase only slightly with $R$ or $U$ either in solution (Fig. 11) or in the solid state. However, the frequency of the $\mathrm{K}^{+}$complexes is anomalously low in solution. The frequencies of the dinactin complexes vary somewhat erratically from one ion to another, but are typically $1-3 \mathrm{~cm}^{-1}$ higher than the corresponding frequencies of nonactin or monactin.

Except for the solid-state $\mathrm{Na}^{+}$complex, the frequency of the $\sim 520 \mathrm{~cm}^{-1}$ (ester C-O-C bend) peak decreases monotonically with $R$ both in solution (Fig. 12) and in the solid state. That this regularity includes even the $\mathrm{NH}_{4}{ }^{+}$ 


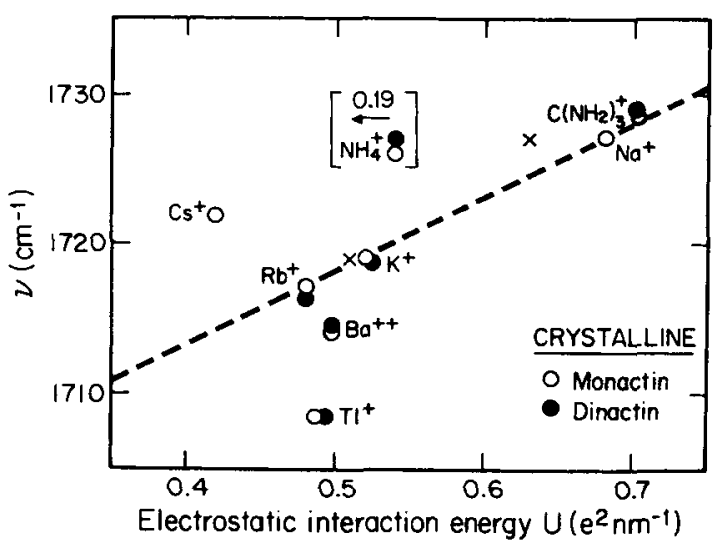

Fig. 11. Ester carbonyl stretch frequency $\nu_{\mathrm{co}}$ as a function of electrostatic interaction energy $U$ for crystalline complexes of monactin (O) and dinactin (๑). The results are similar to those obtained in solution (Fig. 10) except that $\mathrm{Cs}^{+}$and $\mathrm{NH}_{3} \mathrm{OH}^{+}$now lie off of the line defined by the $\mathrm{Rb}^{+}, \mathrm{K}^{+}$, and $\mathrm{C}\left(\mathrm{NH}_{2}\right)_{3}{ }^{+}$ions (the line is roughly parallel to the line of Fig. 10).

ion (which forms hydrogen bonds with the nactin tetrahydrofuran oxygens) and $\mathrm{Tl}^{+}$ion (which may interact partially covalently with the nactins) suggests that the frequency of this mode is sensitive primarily to steric effects, rather than to any specific details of the nactin-cation interaction.

\section{Conformation and Isostericity}

One of the central assumptions in interpreting the chemical properties of the nactins has been that their monovalent cation complexes are isosteric, i.e., "that the overall size and shape of the complex, as well as its externally viewed charge distribution, are the same for all cations." 27 With this assumption, the nactin-solvent interactions are the same for all of the monovalent cation complexes, permitting one to use bulk-phase partition coefficients to study the intrinsic ionic selectivities of the nactins. ${ }^{1,27} \mathrm{~A}$ related problem is the determination of what conformations a complex assumes in different environments. $\mathrm{X}$-ray diffraction measurements have been made on many nactin complexes in the solid state, ${ }^{5-8,28,29}$ but similar $\mathrm{X}$-ray measurements are not possible on the solutions.

Raman spectroscopy may be used both in the solid state and in solution, permitting a study of the relation between the conformations determined by $\mathrm{X}$-ray measurements in the solid state and the conformations present in solution. Conformational differences are reflected in differences in the line frequencies and polarizations observed in Raman experiments. (However, Raman spectra are not directly very sensitive to nactin complex-solvent interactions.) Thus, Raman measurements can probe isostericity in solution: if the conformations of the various nactin-cation complexes are different, they are unlikely to be isosteric. These spectra, except for $\mathrm{Na}^{+}$and $\mathrm{Tl}^{+}$, are highly similar (Figs. 2-5, Tables IM-IIIM), 


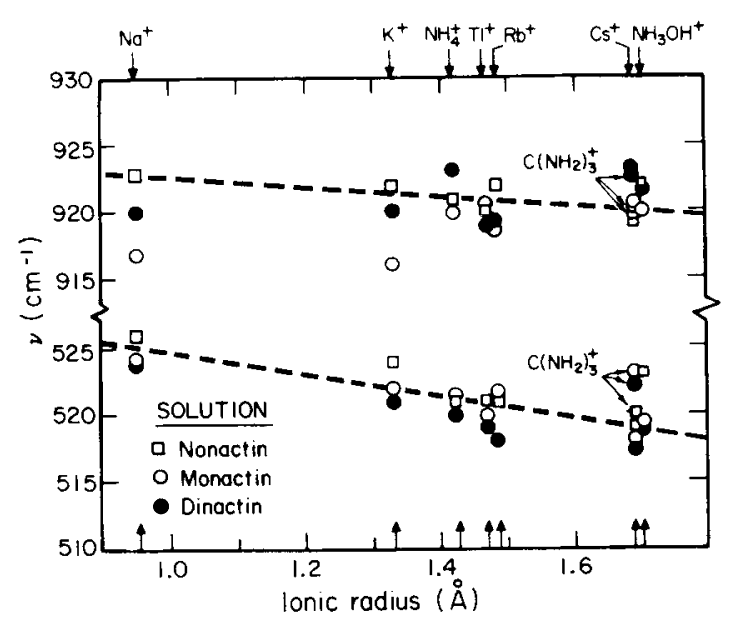

Fig. 12. The frequencies of the $529 \mathrm{~cm}^{-1}\left(\mathrm{C}-\mathrm{O}-\mathrm{C}\right.$ bend) and $920 \mathrm{~cm}^{-1}$ (skeletal deformation) peaks of nonactin ( $\mathrm{\square})$, monactin $(\mathrm{O})$, and dinactin $(\bullet)$ monovalent complexes in $4: 1(\mathrm{v} / \mathrm{v})$ $\mathrm{CH}_{3} \mathrm{OH} / \mathrm{CHCl}_{3}$ solution, plotted as a function of ionic radius $R$. Complexes are identified by the atomic radii of their cations (arrows at top of figure). For clarity, the $\mathrm{C}\left(\mathrm{NH}_{2}\right)_{3}{ }^{+}$data points are identified separately in the figure.

although there are a few minor differences in the $\mathrm{NH}_{4}{ }^{+}, \mathrm{NH}_{3} \mathrm{OH}^{+}$, and $\mathrm{C}\left(\mathrm{NH}_{2}\right)_{3}{ }^{+}$complexes. The $\mathrm{Na}^{+}$complexes: 1) lack a $405 \mathrm{~cm}^{-1}$ band; 2) show no shift in the $520 \mathrm{~cm}^{-1}$ peak upon complexation; 3) exhibit an increase (rather than a decrease) in the polarization of the $520 \mathrm{~cm}^{-1}$ peak; 4) retain a prominent shoulder near $878 \mathrm{~cm}^{-1}$; and, most importantly, 5) display a $\sim 1720,1730 \mathrm{~cm}^{-1}$ doublet in the ester carbonyl stretch region. This suggests that the $\mathrm{Na}^{+}$complex is not isosteric to the other alkali complexes, a result not unexpected from X-ray data and structural chemical considerations. Because the oxygen atoms have a sterically imposed distance of closest approach, a Na+ ion $(R=0.095 \mathrm{~nm})$ is appreciably too small to touch all four nactin carbonyl oxygen atoms simultaneously.

The spectrum of the $\mathrm{Tl}^{+}$complex is also anomalous. In particular, the ester carbonyl peak $\left(\sim 1710 \mathrm{~cm}^{-1}\right)$ is fully polarized, no activity being apparent in the depolarized $(\perp)$ spectrum. This could arise if: 1) the Raman activity of the asymmetric mode were too weak to be observed, or 2) the symmetry of the carbonyl groups about the enclosed ion were different than in the other complexes. Case 1) would imply that the spatial derivatives of the polarizability of the $\mathrm{Tl}^{+}$complexes were different than those of the other complexes, consistent with the presence of different (e.g., partially covalent) intramolecular bonding. In either case, the distribution of electronic charge around the $\mathrm{Tl}^{+}$ion differs from that around other cations. This implies (but does not prove) that the $\mathrm{Tl}^{+}$complex is not isosteric to the others.

The solutions of the complexes with $\mathrm{NH}_{4}{ }^{+}, \mathrm{NH}_{3} \mathrm{OH}^{+}$, and $\mathrm{C}\left(\mathrm{NH}_{2}\right)_{3}{ }^{+}$ generally show a weak peak near $1705 \mathrm{~cm}^{-1}$. This peak may represent a 
further splitting of the coupled $\mathrm{C}=\mathrm{O}$ cation modes by $\mathrm{N}-\mathrm{H}$ stretch and other intracationic vibrations. The hydrogen bonding observed by Nawata et al., ${ }^{7}$ in the tetranactin- $\mathrm{NH}_{4}{ }^{+}$complex may manifest itself in the anomalously high $\nu_{\mathrm{CO}}$ (Fig. 10) in this complex. The lack of tetrahedral symmetry in the $\mathrm{NH}_{3} \mathrm{OH}^{+}$and $\mathrm{C}\left(\mathrm{NH}_{2}\right)_{3}{ }^{+}$ions is not reflected in the Raman spectra of their complexes.

The solid-state spectra of the monactin and dinactin complexes are similar to each other and to their solutions. The solid-state $\mathrm{Na}^{+}$complexes display a sharp, fully resolved $\sim 1709,1730 \mathrm{~cm}^{-1}$ doublet. This suggests that the ester carbonyl groups of the $\mathrm{Na}^{+}$complex are very strongly coupled (X-ray studies on the monactin- $\mathrm{Na}^{+}$complex have previously suggested such a coupling).

Thus all the monovalent nactin complexes, except $\mathrm{Na}^{+}$and $\mathrm{Tl}^{+}$, are conformationally similar in the solid state as well as in solution; it is reasonable to assume most of them are isosteric. Since solvation has little effect on the Raman spectra of the nactin complexes, the conformations adopted in the solid state and solution must be similar. This supports the use of available X-ray crystallographic data in elucidating the properties of the nactin complexes in solution.

\section{NACTIN-BARIUM COMPLEXES}

Nactin- $\mathrm{Ba}^{++}$complexes are highly insoluble in 4:1 (v/v) $\mathrm{CH}_{3} \mathrm{OH} / \mathrm{CHCl}_{3}$ and are immediately precipitated from solutions of uncomplexed nactins by the addition of excess $\mathrm{Ba}(\mathrm{SCN})_{2}$. The bulk of the remaining solvent can be removed by prolonged drying. Our solid-state data are summarized in Figure 13. The tetranactin- $\mathrm{Ba}\left(\mathrm{ClO}_{4}\right)_{2}$ complex was the gift of Dr. K. Ando and Dr. Y. Nawata.

The $\mathrm{Ba}^{++}$complexes resemble the crystalline $\mathrm{Na}^{+}$complexes in that the stretch vibrations of the coordinating nactin carbonyl groups are split into a sharp doublet of $\sim 20 \mathrm{~cm}^{-1}$ separation (Figs. $6(\mathrm{~b})$ and 13). However, the stretch frequencies of the $\mathrm{Ba}^{++}$complexes are considerably $\left(13-19 \mathrm{~cm}^{-1}\right)$ lower, indicative of unusual carbonyl-cation interactions. The increased electrostatic carbonyl-cation interaction could draw the carbonyl groups further inward, thereby decreasing the effective cavity size and making steric constraints more important for divalent ions than for the corresponding monovalent ions. Ester carbonyl stretch frequencies below 1700 $\mathrm{cm}^{-1}$ are rare, yet we find peaks at $1695 \mathrm{~cm}^{-1}$ in monactin-Ba ${ }^{++}, 1692 \mathrm{~cm}^{-1}$ in dinactin- $\mathrm{Ba}^{++}$and $1694 \mathrm{~cm}^{-1}$ in tetranactin- $\mathrm{Ba}^{++}$. This indicates unusually strong coupling between the carbonyl groups and the coordinated $\mathrm{Ba}^{++}$ion.

The monactin- $\mathrm{Ba}^{++}$and dinactin- $\mathrm{Ba}^{++}$complexes also resemble the $\mathrm{Na}^{+}$complexes in having a sharp, isolated ${ }^{10} \mathrm{C}-\mathrm{CH}_{3}$ deformation peak near $1415 \mathrm{~cm}^{-1}$ and a broad diffuse $1335-1365 \mathrm{~cm}^{-1}$ region (partially $\mathrm{CH}_{3}$ wag). Similar features are also found in the uncomplexed nactins [Fig. 6(a)]. Since the nactin methyl groups point outward, they might be influenced 


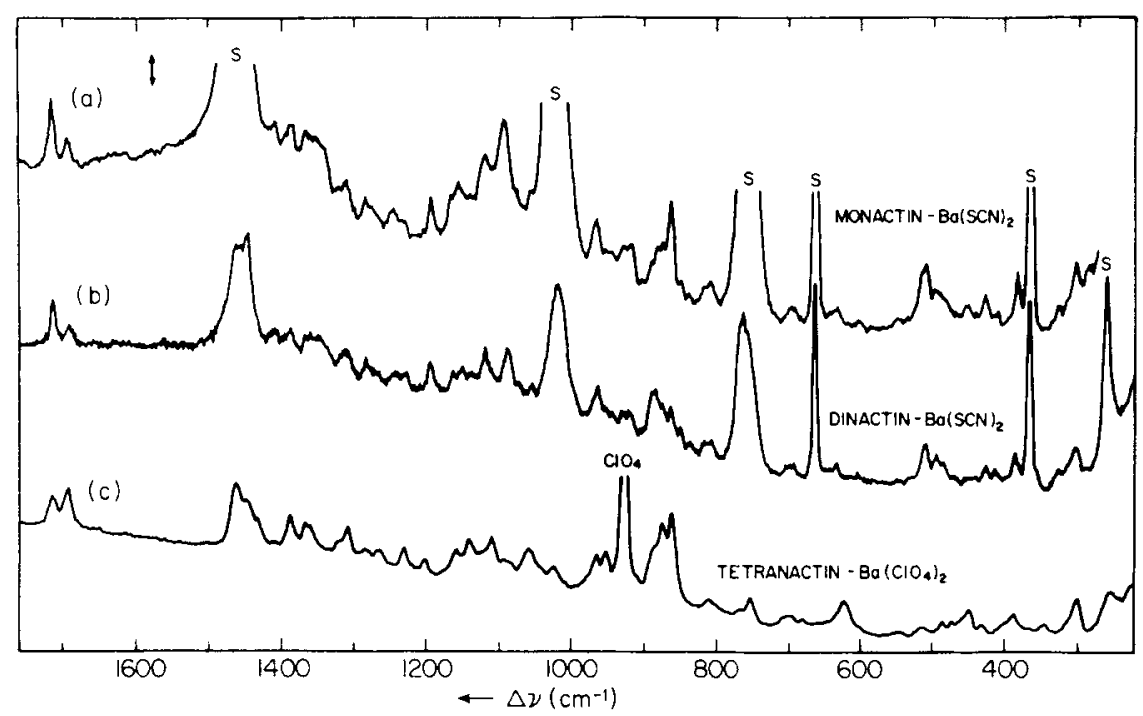

Fig. 13. Raman spectra of crystalline complexes of (a) monactin, (b) dinactin, and (c) tetranactin with $\mathrm{Ba}^{++}$. The distinct splitting and low frequencies observed in the carbonyl stretch region contrast with the single bands observed in spectra of monovalent complexes other than $\mathrm{Na}^{+}$(Figs. 2-6). Vertical arrow represents (a), (b) 100 counts/sec, (c) 300 counts $/ \mathrm{sec}$. Scanning speed $30 \mathrm{~cm}^{-1} / \mathrm{min}$, slit width $4 \mathrm{~cm}^{-1}$, incident power (a), (b) $100 \mathrm{~mW}$, (c) $40 \mathrm{~mW}$, incident wavelength (a) $4880 \AA$, (b) $5145 \AA$, (c) $4579 \AA$. Samples (a), (b) were precipitated from $4: 1(\mathrm{v} / \mathrm{v}) \mathrm{CH}_{3} \mathrm{OH} / \mathrm{CHCl}_{3}$; sample (c) was a single crystal.

by crystal packing; however, the space group of the tetranactin- $\mathrm{Ba}^{++}$ complex $\left(P 2_{1} / a\right)$ differs from that of tetranactin- $\mathrm{Na}^{+}$and uncomplexed tetranactin $(\mathrm{C} 2 / \mathrm{c})$. Unfortunately, similar data are not yet available for monactin and dinactin (tetranactin has no ${ }^{10} \mathrm{C}-\mathrm{CH}_{3}$ groups). The ester $\mathrm{C}-\mathrm{O}-\mathrm{C}$ bend of the nactin- $\mathrm{Ba}^{++}$complexes resembles nactin- $\mathrm{Na}^{+}$by appearing near $510 \mathrm{~cm}^{-1}$ instead of $525 \mathrm{~cm}^{-1}$.

The $\mathrm{Ba}^{++}$complexes differ from all monovalent complexes (including $\mathrm{Na}^{+}$) in several respects. 'The $860-890 \mathrm{~cm}^{-1}$ region (C-O-C stretch) is no longer dominated by the band near $860-870 \mathrm{~cm}^{-1}$ (which appears near 863 $\mathrm{cm}^{-1}$ as in nactin- $\mathrm{Na}^{+}$). Instead, there are several peaks of comparable intensity (Fig. 13), one of which $\left(883 \mathrm{~cm}^{-1}\right.$ in monactin- $\mathrm{Ba}^{++} ; 887 \mathrm{~cm}^{-1}$ in dinactin- $\mathrm{Ba}^{++}$) is $\sim 10 \mathrm{~cm}^{-1}$ lower than in the corresponding $\mathrm{Na}^{+}$ complex. The $1100-1200 \mathrm{~cm}^{-1}$ region is more diffuse than in the monovalent complexes. Monactin-Ba ${ }^{++}$lacks the $401-409 \mathrm{~cm}^{-1}$ peak of other monactin complexes; and dinactin-Ba ${ }^{++}$lacks a peak near $444 \mathrm{~cm}^{-1}$. Conversely, $634 \mathrm{~cm}^{-1}$ and $643 \mathrm{~cm}^{-1}$ peaks appear only in dinactin-Ba ${ }^{++}$ and monactin- $\mathrm{Ba}^{++}$, respectively. Thus, the conformation of the nactin- $\mathrm{Ba}^{++}$complexes may be closely related to that of the $\mathrm{Na}^{+}$complexes, but they are clearly not the same as the nactin complexes of the other monovalent cations. Figure 11 suggests that the nactin- $\mathrm{Ba}^{++}$interaction includes steric, as well as electrostatic, factors. 


\section{APPENDIX}

Some difficulty was caused by spectroscopic changes which take place over several weeks in some nactin crystalline complexes kept at $4^{\circ} \mathrm{C}$. Intense spectral lines appear near 960 , $1000-1040,1360,1385,1640 \mathrm{~cm}^{-1}$ with few appreciable changes elsewhere in the spectrum. These new lines were not seen in uncomplexed crystalline nactins stored for up to one year under the same conditions. Solutions of the complexed nactins in $4: 1(\mathrm{v} / \mathrm{v}) \mathrm{CH}_{3} \mathrm{OH} / \mathrm{CHCl}_{3}$ (kept in sealed capillaries at $4^{\circ} \mathrm{C}$ ) occasionally display a $1640 \mathrm{~cm}^{-1}$ line with $<10 \%$ of the intensity seen in crystalline samples.

In a series of measurements in $\mathrm{CH}_{2} \mathrm{Cl}_{2}$ solution, a $1630 \mathrm{~cm}^{-1}$ peak often appeared within hours after the nactin powder was dissolved. Dilution of uncomplexed nonactin with $\mathrm{CH}_{2} \mathrm{Cl}_{2}$ (from $1.15 \mathrm{M}$ to $0.02 \mathrm{M}$ ) had no effect on the ratio of the 1630 and $1720 \mathrm{~cm}^{-1}$ lines, suggesting that a hypothetical nonactin dimer is not responsible for the $1630 \mathrm{~cm}^{-1}$ peak. On addition of $\mathrm{NH}_{4} \mathrm{Cl}$ and evaporation of the $\mathrm{CH}_{2} \mathrm{Cl}_{2}$, an apparently normal nonactin- $\mathrm{NH}_{4}{ }^{+}$complex was formed, although the $1630 \mathrm{~cm}^{-1}$ peak was still present. We do not have a definitive interpretation for these effects, which we believe to be artifacts. Peaks at 1630,1385, 1360, and $960 \mathrm{~cm}^{-1}$ are consistent with this effect arising from the solvolysis of nactin ester linkages to form a carboxylic acid residue and another, unspecified, group.

We refrained from using solution spectra in which the $1640 \mathrm{~cm}^{-1}$ line was prominent. For the crystalline spectra, this was not always possible; such cases are indicated by an asterisk in Tables IVM and VM.

Samples of the pure nactins were the generous gifts of Dr. B. Stearns (Squibb Institute for Medical Research) and Dr. H. Bickel and Dr. K. Scheibli (Ciba-Beigy, Ltd.); a sample of the tetranactin-Ba ${ }^{++}$complex was kindly provided by Dr. K. Ando and Dr. Y. Nawata (Chugai Pharmaceutical Co., Ltd.). Prof. G. Buchi (M.I.T.) kindly provided a sample of nonactinic acid diester. The authors wish to thank Prof. G. Eisenman (UCLA), Prof. S. Krasne (UCLA), and Dr. K. J. Rothschild for useful conversations, and the late Miss J. Montfort for technical assistance. This project was supported in part by grants from the Research Corporation, and the National Heart and Lung Institute (R. W. Mann, principal investigator).

\section{REFERENCES}

1. Eisenman, G., Szabo, G., Ciani, S., McLaughlin, S. \& Krasne, S. (1973) "Ion binding and ion transport produced by neutral lipid-soluble molecules," Progress in Surface and Membrane Science, vol. 6, Academic, New York.

2. Pretsch, E., Vašák, M. \& Simon, W. (1972) Helv. Chim. Acta 55, 1098-1103.

3. Prestegard, J. H. \& Chan, S. I. (1969) Biochemistry 8, 3921-3927; Prestegard, J. H. \& Chan, S. I. (1970) J. Amer. Chem. Soc. 92, 4440-4446.

4. Kyogoku, Y., Ueno, M., Akutsu, H. \& Nawata, Y. (1975) Biopolymers 14, 1049 1064 .

5. Kilbourn, B. T., Dunitz, J. D., Pioda, L. A. R. Y Simon, W. (1967) J. Mol. Biol. 30, $559-563$.

6. Itaka, Y., Sakimaki, T. \& Nawata, Y. (1972) Chem. Letters (Japan), 1225-1230.

7. Nawata, Y., Sakimaki, T. \& Iitaka, Y. (1975) Chem. Letters (Japan), 151-154.

8. Dobler, M. \& Phizackerley, R. P. (1974) Helv. Chim. Acta 57, 664-674.

9. Phillies, G. D. J., Asher, I. M. \& Stanley, H. E. (1975) Biopolymers 14, 2311-2327.

10. Dobler, M. (1972) Helv. Chim. Acta 55, 1371-1384.

11. Nawata, Y., Sakamaki, T. \& Iitaka, Y. (1974) Acta Crystallogr. B30, 1047-1053.

12. Phillies, G. D. J., Asher, I. M. \& Stanley, H. E. (1975) Science 188, 1027-1029.

13. Asher, I. M., Phillies, G. D. J. \& Stanley, H. E. (1974) Biochem. Biophys. Res. Commun. 61, 1356-1362.

14. Tobin, M. C. (1971) Laser Raman Spectroscopy, Wiley-Interscience, New York, ch. 1,2 . 
15. Tadokoro, H., Kobayashi, M., Yoshidome, H., Tai, K. \& Makino, D. (1968) J. Chem. Phys. 49, 3359-3373.

16. Colthup, N. B., Daly, L. H. \& Wiberly, S. E. (1964) Introduction to Infrared and Raman Spectroscopy, Academic, New York, ch. 9, 10.

17. Snyder, R. G. \& Schachtschneider, J. H. (1963) Spectrochim. Acta 19, 85-115.

18. Snyder, R. G. \& Schachtschneider, J. H. (1963) Spectrochim. Acta 19,117-155.

19. Snyder, R. G. \& Schachtschneider, J. H. (1965) Spectrochim. Acta 21, 169-195.

20. Thompson, H. W. \& Torkington, P. (1945) J. Chem. Soc., 640-645.

21. Katrizky, A. R., Lagowski, J. M .\& Beard, J. A. T. (1960) Spectrochim. Acta 16, 954-963.

22. Herzberg, G. (1945) Infrared and Raman Spectroscopy of Polyatomic Molecules, Van Nostrand Reinhold, New York, ch. 2, 3.

23. Ivanov, V. T., Kogan, G. A., Tulchinsky, V. M., Miroshinikov, A. I., Mikhaleva, I. T., Evstratov, A. V., Zenkin, A. A., Kostetsky, P. V., Ovchinnikov, Y. A. \& Lokshin, B. V. (1973) FEBS Lett. 30, 199.

24. Laato, M. \& Isolato, R. (1967) Acta Chem. 21, 2119-2130.

25. Rothschild, K. J., Asher, I. M., Anastassakis, E. \& Stanley, H. E. (1973) Science 182, 384-386.

26. Asher, I. M., Rothschild, K. J. \& Stanley, H. E. (1974) J. Mol. Biol. 89, 205-222.

27. Krasne, S. J.\& Eisenman, G. (1973) in Membranes, A Series of Advances, vol. 2, G. Eisenman, Ed., Dekker, New York, p. 277.

28. Dobler, M., Dunitz, J. D. \& Kilbourn, B. T. (1969) Helv. Chim. Acta 52, 2573-2583.

29. Nawata, Y. \& Ando, K. Acta Crystallogr. (1972) B27, 1680-1682.

Received January 27, 1976

Accepted June 16, 1976 